BNL -47161

Informal Report

\title{
MARKAL-MACRO:
}

A linked model for energy-economy analysis

\author{
Alan S. Manne and Clas-Otto Wene
}

February 1992

Biomedical and Environmental Assessment Group

Analytical Sciences Division

DEPARTMENT OF APPLIED SEIENCE

BROOKHAVEN NATIONAL IABOHATORY

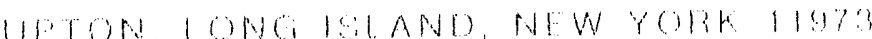




\title{
MARKAL-MACRO:
}

\section{A linked model for energy-economy analysis}

\author{
Alan S. Manne, Stanford University \\ Clas-Otto Wene, Brookhaven National Laboratory and Chalmers University \\ of Technology
}

February 1992
BIOMEDICAL AND ENVIRONMENTAL ASSESSMENT GROUP ANALYTICAL SCIENCES DIVISION DEPARTMENT OF APPLIED SCIENCE BROOKHAVEN NATIONAL LABORATORY ASSOCIATED UNIVERSITIES UNIVERSITY, INC.

Under Contract No. DE-ACO2-76CH00016 with the U.S. Department of Energy

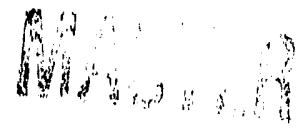


This report was prepared as an account of work sponsored by an agency of the United States Government. Neither the United State Government nor any agency thereof, nor any of their employees makes any warranty, express or implied, or assumes any legal liability or responsibility for the accuracy, completeness, or usefulness of any information, apparatus, product or process disclosed, or represents that its use would not infringe privately owned rights. Reference trademark, manufacturer, or otherwise, does not necessarily constitute or imply its endorsement, recommendation, or favoring by the United States Government or any agency thereof. The views and opinions of authors expressed herein do not necessarily state or reflect those of the United States Government or any agency, contractor, or subcontractor thereof, 


\section{ACKNOWLEDGMENTS}

This project was supported by the Cffice of Program Analysis, Office of Energy Research, and by the Office of Environmental Analysis, Office of Policy, Planning and Analysis, U.S. Department of Energy.

The work was performed when one of the authors (Wene) was a visiting scientist at Brookhaven National Laboratory. He thanks Dr. George Jordy for suggesting this stay, and for insisting that MARKAL should have an economic driver. He also thanks Dr. Leonard Hamilton and his colleagues at the Biomedical and Environmental Assessment Group for their support during his visit. 


\section{TABLE OF CONTENTS}

1. Introduction

1.2 Purpose

1.2 The models

1.3 Organization of this report

2. MARKAL, MACRO and the linkage approach

2.1 Overview of the linkage

2.2 MARKAL

2.3 MACRO

3. The specifics of hardlinking

3.1 GAMS and OMNI

3.2 Treatment of capital charges

3.3 Benchmarking to base year data (calibration)

4. Demonstration with a restricted U.S. database

4.1 Two-way linkage

4.1.1 Economic growth and price-demand interactions

4.1.2 Endogenous and exogenous demands

4.1.3 Prices

4.2 Demand technologies and the representation of conservation

4.3 Primary energy

5. Summary and conclusions

Appendix A

1. MACRO decision variables and notational conventions

2. MARKAL decision variables and constraints

3. MACRO constraints

Appendix B

Computer listings of excerpts from the following "include" files:

SETS.INC

NBROWS.INC

MAT.INC

COST.INC

DEMAND.INC

MACRO.INC 


\section{Introduction}

\subsection{Purpose}

MARKAL-MACRO is an experiment in model linkage. This new tool is intended as an improvement over existing methods for energy strategy assessment. It is designed specifically for estimating the costs and analyzing the technologies proposed for reducing environmental risks such as global climate change or regional air pollution.

The greenhouse gas debate illustrates the usefulness of linked energy-economy models. A central issue is the coupling between economic growth, the level of energy demands, and the development of an energy system to supply these demands. The debate is often conrected with alternative modeling approaches. The competing philosophies may be labeled "top-down macroeconomic" and "bottom-up engineering" perspectives.

Do macroeconomic models, with their descriptions of effects within the total economy but fewer technical details on the energy system, tend to overestimate future energy demands? Conversely, do engineering models, ignoring feedbacks to the general economy and non-technical market factors but containing rich descriptions of technology options, tend to take too optimistic a view of conservation and the use of renewable energy sources? Or is the principal difference that the engineering models ignore new sources of energy demands, and that the macroeconomic models ignore saturation effects for old categories of demands?

An efficient modeling tool must have the scope and detail to match the width and depth of the policy problem being analyzed. If we are to cope with major environmental risks (e.g., the possibility of global climate changes), there must be long-range, fundamental changes in the energy system. For an analysis of these changes, the modeling tool must be able to capture the complex network of relations within the energy system, ss well as the opportunities of new or improved technologies.

Changes in the energy system may lead to increased energy costs and changing relative prices for energy carriers. If energy prices rise, there will be a considerable amount of price-induced conservation. A transition would require the reallocation of resources from other parts of the economy. In this way, it could affect capital formation and reduce economic growth. Ultimateiy this would affect the aggregate level of economic activity and the mix of energy demands. To analyze these indirect effects of emission reductions, we need modeling tools that will integrate the macroeconomic and the systems engineering approach. 


\subsection{The Models}

Good documentation is available for MARKAL and for MACRO. These each have a proven track record for energy and environmental use. See Rowe and Hill (1989), Johnsson et al. (1992) and Manne and Richels (1992).

Both models are dynamic. That is, they are solved under the assumption that there is perfect foresight with respect to changing technologies and economic conditions. The alternative would be to adopt recursive dynamics in which decisions are made separately for each time period. The recursive approach has several advantages, but like the cobweb model of agricultural systems, it has the disadvantage of a tendency toward "overshoot and collapse".

MARKAL is a systems engineering (physical process) analysis built on the concept of a Refe:ence Energy System, RES. See Marcuse et al. (1976) and Fishbone et al. (1983). MARKAL allows a detailed description of existing and alternative energy technologies and of existing and alternative paths of energy carriers from their source - through different conversion technologies until the point of final use. The MARKAL structure makes it possible to build in supply curves of technical conservation. See Wene (1980). Often, however, it was supposed that comprehensive supply curves were too difficult to estimate, and price-induced conservation options were therefore omitted.

MARKAL is solved by means of dynamic linear programming. In most applications, the end use demands are fixed, and an economically efficient solution is obtained by minimizing the present value of the energy system's costs throughout the planning horizon.

General!y, MARKAL has been used in a stand-alone mode, but there have been a number of experiments with informal linkage to other models. The first work along these lines was reported by Hoffman and Jorgensen (1977). For subsequent work, see Berger et al. (1987) and Yasukawa et al. (1989). We are unaware of previous efforts at formal linkage ("hardlinking") between MARKAL and a long-term macroeconomic growth model.

MACRO is a macroeconomic model with an aggregated view of long-term economic growth. The basic input factors of production are capital, labor and individual forms of energy. The economy's outputs are used for investment, consumption and interindustry payments for the cost of energy. Investment is used to build up the stock of capital. The model clearly distinguishes between autonomous and price-driven conservation.

MACRO is solved by nonlinear optimization. It uses the criterion of maximum discounted utility of consumption to select among alternative time paths of energy costs, macroeconomic consumption and investment. 
MACRO is "dynamic" in the same sense as MARKAL: it uses look-ahead features for choices thoughout the planning horizon. This implies, for instance, that the investment decisions lead to equal benefits for the consumer from an additional dollar's worth of current consumption and the future consumption generated by an additional dollar's worth of investment.

Both MACRO and MARKAL are based on the concept of a single representative producerconsumer. This means that there are no tax or subsidy wedges between the marginal costs of consumption and of production. Neither model provides a direct calculation of impacts on individual industries at, say, the two-digit SIC level. Hitherto, MACRO has been used only in conjunction with ETA, a highly aggregated Energy Technology Assessment model.

In describing the development of the energy system and providing information about energy costs, MARKAL fulfills the same role as ETA. MARKAL has considerably more technological detail than ETA, but ETA has a more sophisticated treatment of nonlinearities in the dynamics of market penetration. ETA features only 8 electric and 9 nonelectric technologies. There is little or no description of the conversion processes that lie between primary energy sources and the end-use demands.

The linkage experiment is based on a U.S. demonstration version of MARKAL - one containing about 15 supply technologies, 30 demand technologies and 10 different fuels. It also incorporate seasonal and diurnal variations in the demands for electricity and district heating. It distinguishes between 13 different useful energy demands. These are viewed as primary inputs into the MACRO production function.

The full-scale U.S. version of MARKAL currently contains descriptions of more than 100 technologies, and time is analyzed in five-year steps. To reduce computer time, this experimental version of MARKAL-MACRO has fewer technologies and fewer time periods. We use ten-year increments from 1990 through 2020.

Useful Energy Demands are exogenous parameters in the stand-alone MARKAL. As a result of the two way linkage, useful energy demands become internal parameters determined by macroeconomic growth and by conservation (both autonomous and price-driven). Capital accumulation and economic growth are affected by changes in energy costs, but interfuel substitution lies within the domain of MARKAL. 


\subsection{Organization of this report}

Section 2 contains a more detailed descriptions of the MARKAL and MACRO models and the concepts underlying the linkage of the two models. Section 3 describes some of the technical difficulties that had to be overcome, and section 4 provides illustrative numerical results. The concluding section contains our suggestions for future work.

\section{MARKAL, MACRO and the linkage approach}

\subsection{Overview of the linkage}

Figure 1-1 provides an overview of the connections between the two components of the system. To minimize the need for structural changes in the two original models, we have introduced only two types of linkage. There are physical flows of energy from MARKAL into MACRO, and there are energy cost payments from MACRO into MARKAL. This is much the same approach that has proven itself in ETA-MACRO. The principal difference is that the physical flows of energy are defined here as "Useful Energy Demands". They are exogenous to the stand-alone version of MARKAL, but endogenous to the linked model. The costs of energy supply appear in the objective function of MARKAL, but enter into MACRO through the period-by-period constraints governing the allocation of the economy's aggregate output between consumption, investment and energy cost payments.

The linkage between MARKAL and MACRO is based upon one key idea - the concept of an economy-wide production function. Just as with any other attempt at understanding the complexities of an economic system, there are pros and cons in adopting this particular abstraction. The principal advantage is that this enables us to make a direct link between a physical process analysis and a standard long-term macroeconomic growth model. The principal disadvantage is that we cannot make a direct connection with the interindustry composition of demands (described, for example, in terms of two-digit SIC codes).

For demonstrating the feasibility of these ideas, the model is benchmarked against U.S. data for a base year of 1990, and the projections cover ten-year time intervals from 2000 through 2020. This is an intertemporal rather than a recursive system. Expectations affect the accumulation of capital over time. Savings and investment decisions are modeled through the maximization of discounted utility. 


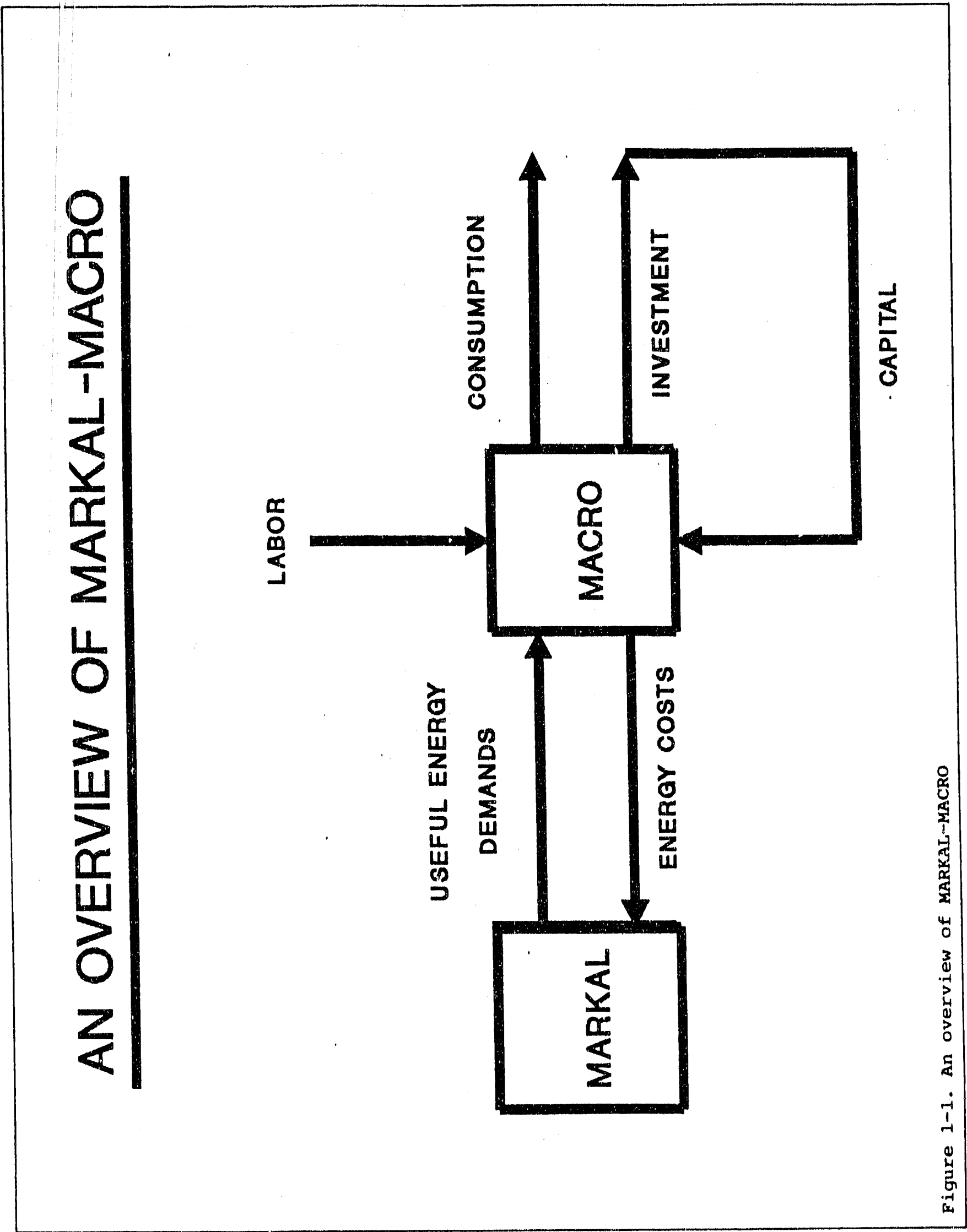




\section{$2.2 \quad$ MARKAL}

The MARKAL (MARKet ALlocation) model was developed between 1976 and 1981 as a multinational collaborative effort within the framework of the International Energy Agency. See Fishbone et al. (1983). MARKAL is a technologically oriented linear programming model of the energy sector. The system boundaries, are defined by the user. The model was used for studies of the national energy systems for most countries within the IEA. See Tosato et al. (1084). It was also used to support energy planning in developing nations such as Brazil, China, Ecuador and Indonesia. It was applied to regional energy systems in Canada and community energy planning in Sweden. See, respectively, Berger et al. (1987) and Wene (1989).

The RES (Reference Energy System) concept is central to MARKAL. The RES is a flowchart showing all possible routes from each source of primary energy through various transformation steps to each end-use demand sector. The flowchart can be extended to show emissions when energy is transported or converted from one form to another. MARKAL describes these routes, energy conversion and distribution technologies and also emissions control options. The model identifies those routes and technologies that best satisfy the overall objectives of the energy system. The model describes the technical and economic properties of each technology - und may also describe the technical and behavioral constraints upon their implementation. Typical parameters include energy efficiency, emissions, operating and maintenance costs, initial investment and availability factors.

The most common formulation is to satisfy the end-use demands at a minimum present value of system costs. Typically, the real annual discount rate lies between $4 \%$ and $8 \%$. The modeling horizon is $25-40$ years, usually described in time steps of sither 3 or 5 years.

MARKAL is a data-driven model. The numerical results depend heavily upon the input assumptions. The logical structure is relatively simple. Most constraints describe annual, seasonal or diurnal energy balances. There are constraints ensuring that enough capacity will be built to meet the demands for secondary and tertiary energy carriers, and there are other constraints allowing for scheduled and unscheduled maintenance. The input data can be grouped into four broad categories:

- Technology categorizations. The scale may be either large or small. Both price-induced and non-price conservation may be included in the definition of a technology. A typical large-scale unit would be an integrated coal-gasification combined-cycle electricity generating station. Heat pumps and electric cars are examples of small-scale end-use technologies. Conservation options might include double-pane windows and high-efficiency oil burners. Technology characterizations represent most of the input data to a MARKAL model. 
- Sources of primary energy. Primary energy may be defined in terms of oll and gas wells, coal and uranium mines, and biomass raw material. These sources are usually characterized by supply curves showing the annual potential supply and extraction costs. For exhaustible resources, there may be cumulative constraints indicating the total of proven reserves and additional resources that might be available over the planning horizon. Import and export options are also included here.

- Useful energy demands. In the stand-alone version of MARKAL, end-use demands are specified exogenously for all time periods. The demands may be defined either in terms of energy requirements or in terms of an energy service, e.g. vehicle-kilometers of automotive transport or tons of steel. The demands need not refer to a specific fuel. MARKAL has built-in options for alternative fuels and end-use utilization technologies.

- Environmental constraints. Environmental constraints may be introduced as a physical cap on emissions such as sulfur dioxide, nitrogen oxides or carbon dioxide. The dual variables on these constraints may be interpreted in terms of emission fees or taxes.

\subsection{MACRO}

The MACRO production function is characterized by smooth substitution. With its nonlinear form, a small price change leads to a small change in the mix of inputs or outputs. The structure leads to qualitatively different results from those generated by a linear program such as MARKAL. With linear programs, it is typical to observe "penny-swiiching" effects. A small change in prices will lead either to no effect whatever - or else to a large change in the composition of inputs or outputs.

The inputs to the production function consist of capital, labor and useful energy demands. Capital, labor and energy may each be substituted for the other, but there are diminishing returns to the substitution process. This is the way in which the model incorporates price-induced energy conservation. In addition, there is the possibility of autonomous improvements in energy efficiency (AEEI, for short). These are non-price factors that could reduce energy demands per unit of gross output.

To avoid the econometric estimation of many parameters, the production function is a nested CES (constant elasticity of substitution) form. At the top level, there is a capital-labor aggregate that may be substituted for an energy aggregate. At the bottom level, there is a unitary elasticity of substitution between capital and labor, and the energy aggregate is separable. This structure implies that capital and labor may be substituted directly for each other, e.g. through the automation of laborintensive tasks. The higher the wage rate, the more attractive it becomes to adopt automation. 
With this specific form of CES nesting, price-induced conservation operates by lowering the marginal productivity of capital and labor. That is, if there is a rise in energy costs, the production function allows us to adapt by substituting more capital and labor in place of energy. Moreover, each category of useful energy demands may be substituted for the other. In effect, we assume "want independence" between them. See Frisch (1959). The ease or difficulty of price-induced conservation is governed largely by the value adupted for ESUB (tlis elasticity of substitution between the energy and the capital-labor aggrega(ces).

The economy's long-term growth rate is determined primarily by the value assumed for the growth of the labor force and its productivity. The combination of these two factors is described in terms of labor "efficiency units". For shorthand, this is the "potential" growth rate of the economy. It is a major determinant of the utility discount rate employed in the MACRO objective function. If there is a rise in energy costs, it will be optimal to reduce consumption and investment. With a drop in capital formation, the realized growth rate will then fall short of the potential.

\section{The specifics of hardlinking}

\subsection{GAMS and OMNI}

MARKAL-MACRO is written in GAMS (a generalized algebraic modeling system). See Brooke et al. (1988). To solve a single case, it takes about 6 minutes on a $25 \mathrm{mHz}$ desk-top 486 computer. This is about $50 \%$ more time than is required to solve MARKAL as a stand-alone linear program.

MARKAL is written in OMNI, a character-oriented language, whereas GAMS is oriented toward the use of sets. The difference is subtle. OMNI is intended for applications in which the numerical entries may be varied, but the logical structure remains substantially unchanged. By contrast, GAMS is designed for use by those who are not computer specialists, but who place a high value on being able to change the model's structure.

The OMNI system generates the entire linear programming matrix of MARKAL in a standard MPS (mathematical programming system) format, but GAMS was not designed so as to be able to read this format directly. Instead, a special MPS to GAMS conversion program $"$ as written so that the MARKAL submodel could be taken over directly with a minimum number of changes. For further details on the model formulation and the conversion process, see Appendices A and B. 


\section{2}

\section{Treatment of capital charges}

In earlier applications, the MARKAL and MACRO submodels differed in their terminal conditions and also in their treatment of capital charges. MARKAL viewed investments as one-time expenditures that provide a stream of capacities available during subsequent time periods. It it survives past the horizon date, an investment leads to a salvage credit during the terminal period. This is sometimes said to be a "dual" terminal condition.

By contrast, MACRO employs a primal terminal condition. It specifies that the rate of investment in the final period must be large enough to allow post-horizon growth to proceed at a constant geometric rate. It allows for investment costs through capital recovery factors - with a uniform annual amortization charge throughout the useful life of plant and equipment. To reduce horizon effects in the linked model, we adopted the MACRO conventions for post-horizon growth and for investment costs. Incidentally, even before the merger, both models were using the identical numerical value of the discount rate for investment purposes $-5 \%$ annually as the real cost of capital (net of inflation) to the U.S. economy.

MARKAL and MACRO allow for the durability of capital goods, but each in a somewhat differently. In MARKAL, there is a fixed value assigned to the useful life of each distinct technology, and there is a uniform amount of capacity available from that investment dering each year of its life span. There is an explicit distinction between the decision variables that govern investment and thuse that govern the use of capacity. In MACRO, this distinction is not drawn; depreciation is viewed as a geometric decay process - typically a decay rate of $5 \%$ annually. This reduces the number of decision variables and constraints and therefore reduces the time required for computations, but it means that we do not have the option of abandoning excess capacity in the form of obsolete capital equipment. In the linked model, we follow the original MARKAL formulation for the energy sector and follow the MACRO formulation for the economy-wide capital stock.

\subsection{Benchmarking to base year data (calibration)}

The MACRO production function contains a capital-labor term and an energy aggregate. The user must specify an overall elasticity of substitution between capital-labor and energy. Each of MARKAL's useful energy demands ente. as inputs into the energy aggregate. F'or puiposes of this demonstration, there were 13 demand categories. Thus, benchmarking involved estimation of a coefficient for the capital-labor term and for each of the 13 components in the energy aggregate. 
To calibrate the MACRO submodel, the following base year data were required: GDP, aggregate energy costs, the demand and the price for each category of useful energy. Estimates must also be provided for the capital-GDP ratio, the depreciation rate, and capital's value share of GDP. The three latter parameters must be consistent with the net rate of return on capital that is assumed in the stand-alone version of MARKAL.

For purposes of this demonstration, the base year was 1990. The GDP was readily available from standard statistical sources. For 1990, the useful energy demands and prices were taken from the stand-alone version of MARKAL. These prices are the undiscounted marginal costs (also known as shadow prices) tak $n$ from the dual solution to this programming model. To illustrate the robustness of this benchcmarkin fo procedure, Table 3-1 compares the energy prices from the stand-alone MARKAL and the linked MARKAL-MACRO model. The two sets of prices differ slightly from each other, but are reasonably consistent. During the course of our experiments with MARKAL-MACRO, we have encountered instances where the primal solution is degenerate, nd the dual solution is therefore indeterminate. Some of these difficulties are traceable to current practices for describing base year residual capacity in the MARKAL database. Solutions are indeterminate when the upper and lower bounds on activity levels are set too close to each other. Other types of difficulties arise when the demand and/or supply categories consist of heterogeneous rather than homogeneous items.

The MARKAL-MACRO calibration procedure gives the modeler some degrees of freedom in the choice of demand structure, but it also requires greater attention to the quality of the base year data. Current validation procedures must be extended to include base year economic activities such as the energy system's investment levels, import costs and export revenues. 
Table,3-1. Base year energy prices generated by MARKAL and MARKAL-MACRO

(1990 base year, prices in 1980 U.S. dollars per GJ)

Useful energy demand category

II Iron and steel metallurgy

ID Industrial process heat

IE Industrial electricity

IZ Hydrocarbons for non-energy use

R1 Residential space heat

R2 Residential hot water

R3 Residential air conditioning

R6 Commercial space heat and hot water

R8 Commercial air conditioning

RA Residential and commercial appliances

T1 Rail/truck/bus transport

T4 Automobile transport

T9 Air and ship transport
MARKAL

$\$ / G J$

15.35

4.69

12.62

3.08

10.59

6.65

13.62

9.79

15.04

12.91

3.67

$\because 1.27$

10.07
MARKAL-MACRO

$\$ / G J$

14.42

4.61

11.69

3.08

9.17

6.30

12.20

9.60

13.70

11.81

3.67

21.27

10.07 


\section{Demonstration with a restricted U.S. database}

These computer runs are intended to demonstrate some important aspects of the MARKALMACRO linkage, but the results are not yet ready to be used as the basis for energy strategy assessments. Some database revisions were made, but only to ensure a consistent benchmarking procedure. The revisions were necessary because some data design practices, which are both appropriate and efficient for the stand-alone MARKAL, may lead to erroneous results for MARKALMACRO.

We have taken an existing database, reduced it in size by using decades in place of five-year time intervals, and by combining some of the less important energy technologies, and then checked the performance of this aggregated model. The next logical step would be to use the experience from the demonstration case to revise the existing procedures for data management and for quality control. We recommend that these procedures be revised before enlarging the database to contain more detailed information about the energy system and technological options.

This demonstration relies upon the most current US-MARKAL database available at Brookhaven National Laboratory. In down-sizing the Reference Energy System, we have taken advantage of an existing data set developed for demonstration purposes. The energy flows for the 1990 base year were updated by using information from the Energy Information Administration. We revised the physical flows but not the cost data.

Our initial experiments with the linked model indicated that it was not sufficient to update the energy flows. The current practice of describing residual capacities had to be changed so that the MARKAL submodel would provide an appropriate estimate of the base year's capital charges. For purposes of this demonstration, we adopted a simple procedure for correcting the residual capacities. This procedure should be further refined and validated. We have not altered any of the technology characterizations that appeared in the database. Many of these estimates were updated during the past few years, but a thorough review would be desirable before proceeding further. Such a review would greatly facilitate future analyses.

In section 4.1, we focus on energy demands and costs. These constitute the interface between the two submodels. We try to disentangle the effects of economic growth and of changes in energy prices. The section also contains a comparison between the exogenous demand inputs to MARKAL and the endogenous demand outputs from MARKAL-MACRO. The comparison illustrates how the linked model can be used to investigate features such as demand saturation.

We have already mentioned the routines for dealing with residual capacity. We now discuss them in further detail, and show how they may distort the benchmarking (calibration) of the linked 
models. MACRO incorporates price-induced and autonomous conservation through parameters that define an economy-wide production function. MARKAL describes all conservation in terms of specific technologies. To avoid double counting, it is important that common procedures be developed for both models. Section 4.2 describes the demand technologies and the representation of conservation. For further work, we recommend that price-induced and autonomous conservation be handled by the MACRO submodel for useful energy demands, and that interfuel substitution and technology switching be handled within MARKAL. After establishing a base case, one could reintroduce price-induced conservation options within MARKAL - but only for those demand categories for which there is inclusive and detailed information available.

Section 4.3 compares the primary energy demands and emissions of carbon dioxide from the stand-alone and the linked models. Most of the differences in demand for specific energy carriers are the direct consequences of differences in the projection of useful energy demands.

\subsection{Two-way linkage}

\subsubsection{Economic growth and price-demand interactions}

MARKAL is driven by exogenously given useful energy demands (UED), Critics often note that these demands are independent of prices. Although MARKAL will show how the different energy demands can be satistied at the lowest possible cost, the level of energy services demanded from the energy system is independent cf the price that the consumer must pay for these services. The model user may introduce technical conservation options as explicit activities. The demands may also be adjusted by external "add factors", but these are arbitrary and do not go to the core of the problem. The lack of demand-price interactions is particularly troublesome for national or regional models when we anticipate that there will be considerable changes in relative prices. $\mathrm{CO} 2$ emission restrictions might well induce such price changes.

Figures 4-1A and $\mathrm{B}$ illustrate how the MARKAL-MACRO linkage affects the relation between energy demands, prices and aggregate economic growth. For each demand category, these figures show how marginal costs and useful energy demands (UED) change between the beginning and the end of each successive decade. The marginal costs for the demand categories are the same as those discussed earlier in section 3.3. The UEDs for MARKAL are taken from the exogenous demand projections. Those for MARKAL-MACRO are calculated endogenously, but they depend in turn upon the aggregate rate of economic growth, the autonomous energy efficiency increase (AEEI), wie elasticity of priceinduced energy substitution (ESUB) and the changes in energy prices. 


\section{CORRELATIONS SP AND UED RATIOS}

From MARKAL-MACRO (Demo Cose)

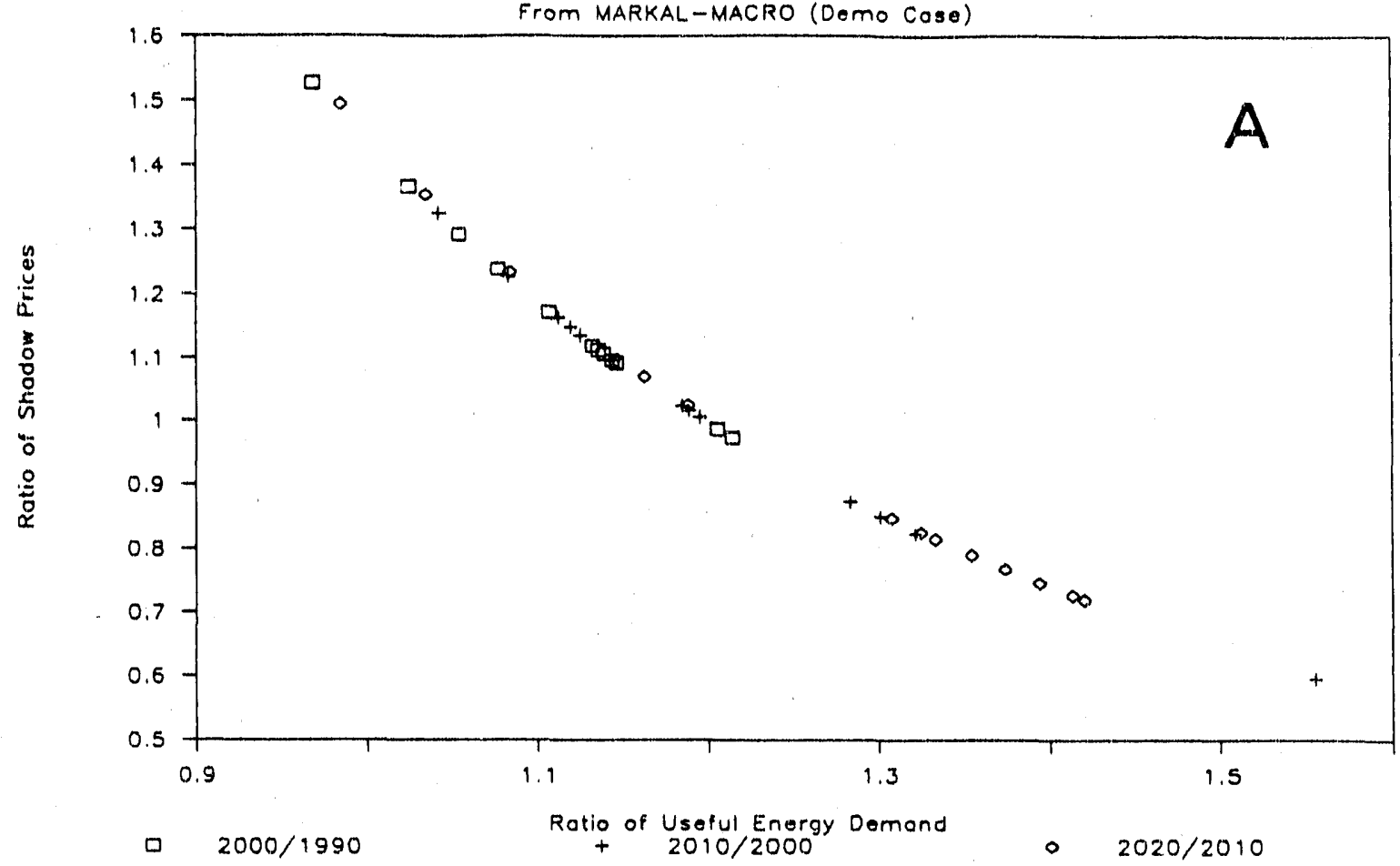

CORRELATIONS SP AND UED RATIOS

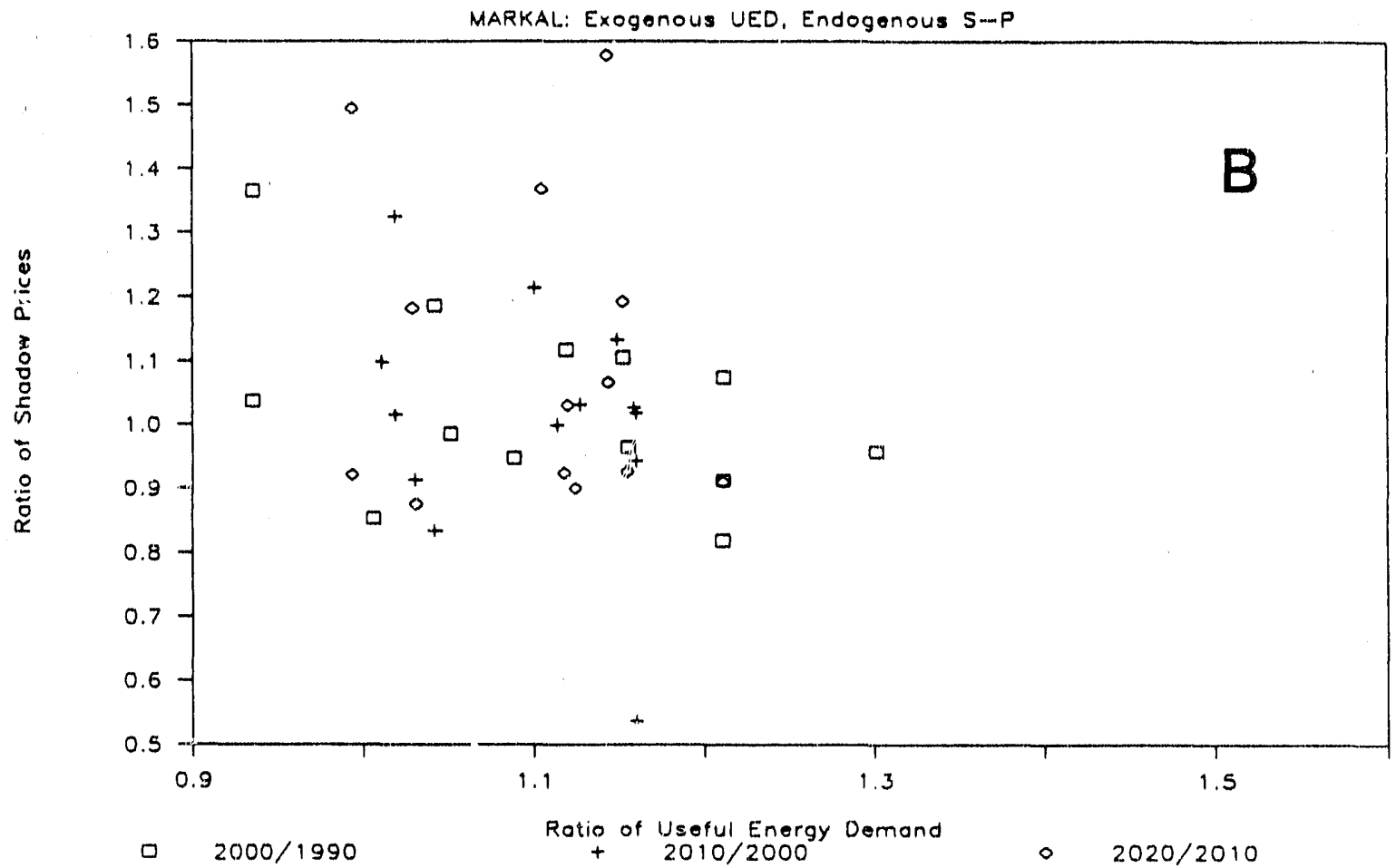

Figure 4-1A,B. Correlations between shadow prices and UED growth - three decades.

For each decade and each demand category, this igure ahow the relation between the change in shadow prices (marginal costs) and the change in Useful Energy Demands. With three decades and 1.3 demand categories, there are altogether 39 data points. The top figure shows the results from the MARKAL-Macro demonstration case. The bottom figure show the ratios for the externally spocified demands and the internally generated shadow prices for the stand alone MARKAL model. 
The MARKAL diagram shows no correlation between changes in marginal costs and changes in useful energy demands. By contrast, the MARKAL-MACRO diagram shows that all data points lie along curves that can be described by power functions. There are in fact three such curves, one for each pair of consecutive periods: 1990-2000, 2000-2010, 2010-2020. Figures 4-2A, B and C indicate that all results can be described by the same power function:

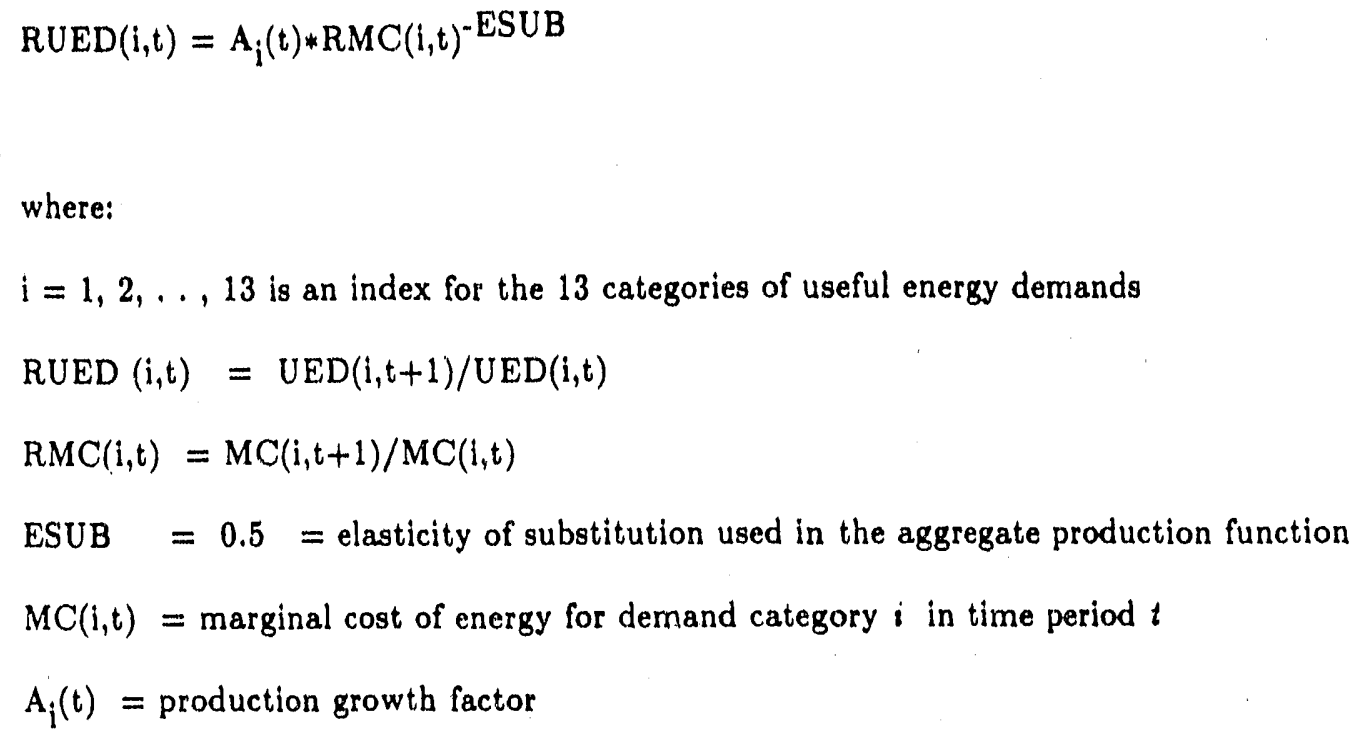

The factor $A_{i}(t)$ depends primarily upon the aggregate economic growth rate, but it also depends on the AEEI factor assumed for demand category i. If energy prices remain constant, it would equal RUED(i,t), the growth index between period $t$ and period $t+1$. Thus, $A_{i}(t)$ shows how useful energy demand growth depends upon autonomous conservation and also upon aggregate macroeconomic activity. The power function term indicates how demand growth may be decoupled as a result of changing prices. In this example, we have assumed that the potential GDP growth rate is $2.0 \%$ annually from 1990 through 2020 , and that there will be autonomous efficiency improvements of $0.5 \%$ in all demand categories. To a first approximation, we therefore expect all demands to grow by $1.5 \%$ annually. The actual demand growth rates $\mathrm{A}_{\mathrm{i}}(\mathrm{t})$ are a bit higher. They can be compared with the growth in the key macroeconomic variables shown in Tables 4-1 and 4-2. These growth rates are outputs from, not inputs to the MARKAL-MACRO model. 
SP and UED Ratios $1990-2000$

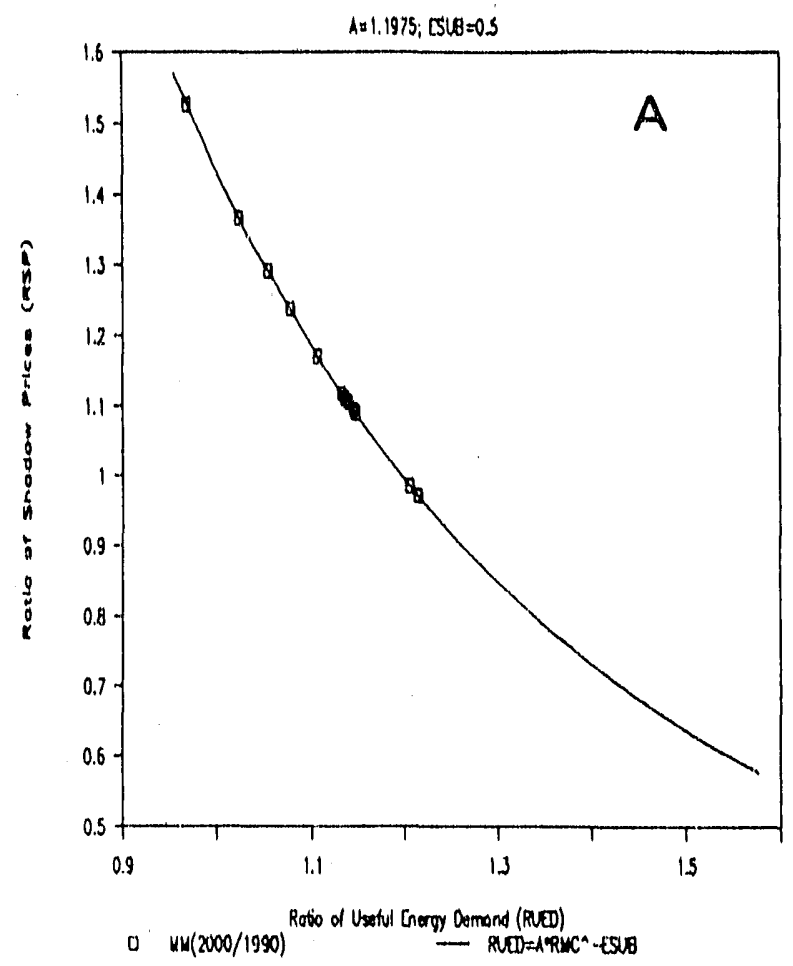

SP and UED Ratios 2010-2020

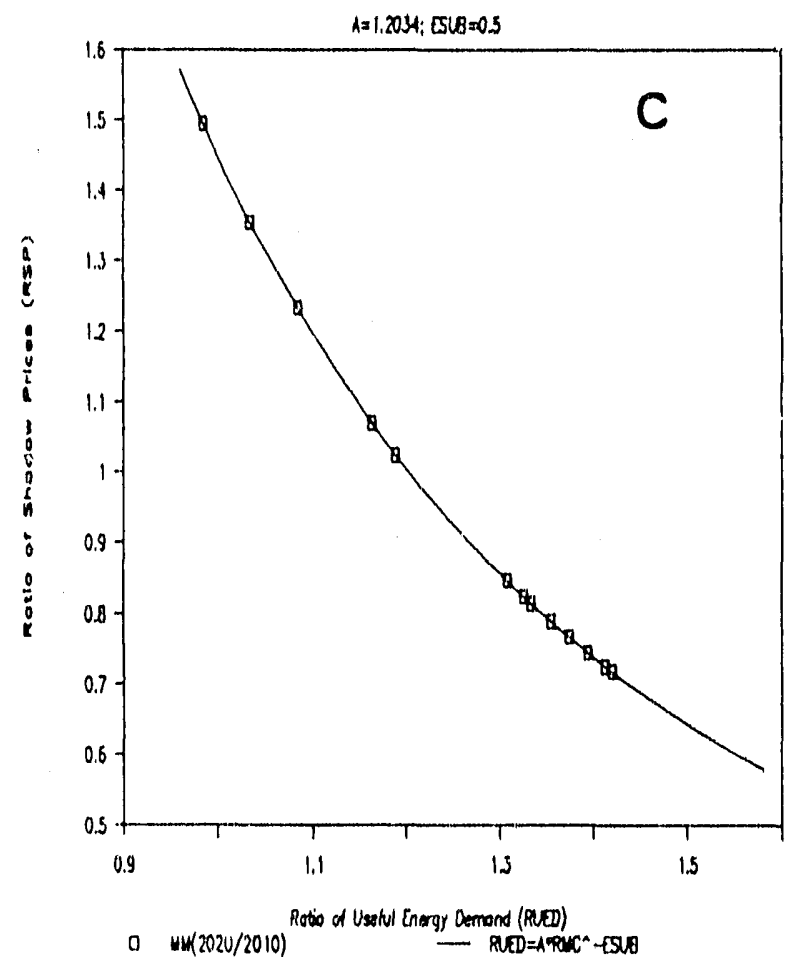

SP and UED Ratios 2000-2010

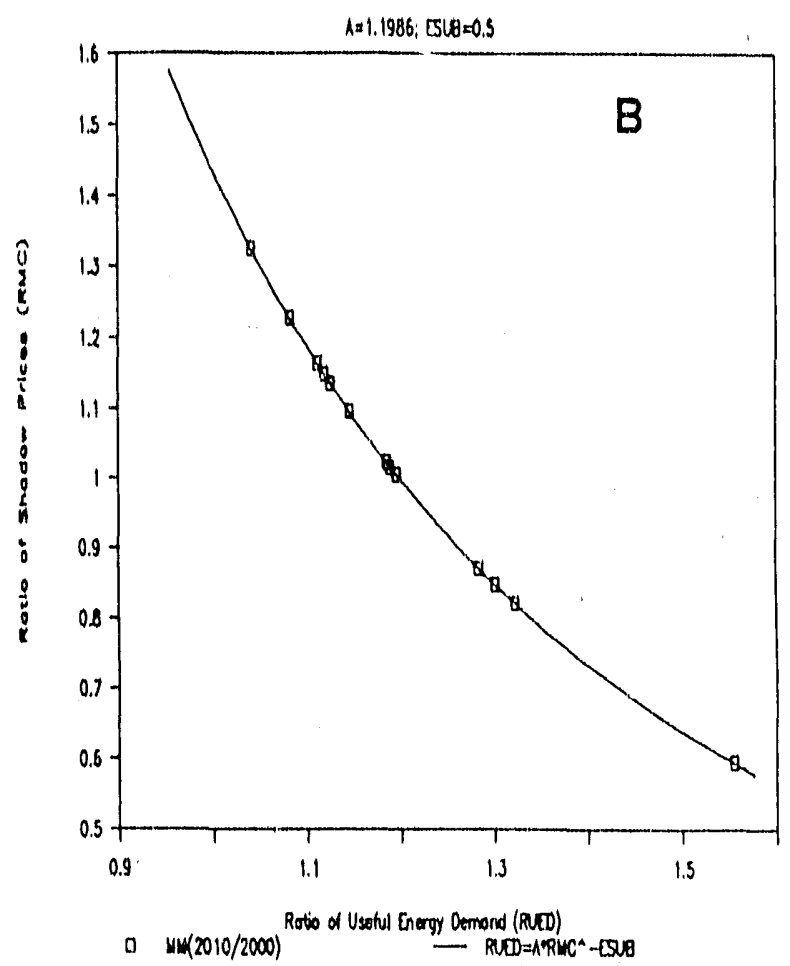

Figure 4-2A,B,C.

Comparisons between power function and MARKAL-MACRO result - by decader.

The IInes axe calculated from the power function and the squares refer to the MARKAL-iLACRO demonetration. The MARKAL-MACRO regults are gansitive to assumptions about the base year reference price. If thexe are larga deviations from the power function that cannot be explained by differences in AEEI rates, the model uger 1 advised to recheck the benchmarking procedure. 
Table 4-1

Useful energy demand growth at constant energy prices

\begin{tabular}{lllll}
\hline & $1990-2000$ & $2000-2010$ & $2010-2020$ & $1990-2020$ \\
$\begin{array}{l}\text { UED } \\
\text { growth factors }\end{array}$ & 1.198 & 1.199 & 1.203 & 1.727 \\
$\begin{array}{l}\text { Annual growth } \\
\text { rates, \% }\end{array}$ & 1.82 & 1.83 & 1.87 & 1.84 \\
\hline
\end{tabular}

Table 4-2

Annual growth rates for macroeconomic variables, $\%$

\begin{tabular}{lllll}
\hline & $1990-2000$ & $2000-2010$ & $2010-2020$ & $1990-2020$ \\
Gross Domestic Product & 2.04 & 2.16 & 2.28 & 2.16 \\
Consumption & 1.89 & 2.26 & 2.26 & 2.14 \\
Investment & 2.79 & 1.68 & 2.32 & 2.26 \\
Energy Costs = EC & 2.26 & 1.64 & 1.16 & 1.69 \\
Gross Production $=$ & & & & \\
$\quad$ GDP + EC & 2.08 & 2.08 & 2.12 & 2.09
\end{tabular}


There are varlous possible explanations for the discrepancles between the potential and actual growth rates of the macroeconomic variables. The decline in the growth rates for energy costs may be due to overoptimism in the MARKAL database about the prospects for increasing the efficiency of energy use. The MARKAL database itself contains assumptlons about non-price conservation, and apparently the autonomous Improvements are much larger than indicated by our explicitly specified AEEI parameter of $0.5 \%$ annually. A more detalled analysis of the production function shows that the rates $A_{1}(t)$ are affected by factors other thas the GDP growth rate. They depend upon all four macroeconomic variables: gross production, capital, labor and energy costs. There may be other, more technical explanations for these discrepancies. For one thing, there could be slight changes in the results if we were to employ shorter time intervals - five years instead of decades.

For the initial experiments with the linked model, the database was updated only by revising the energy flows for the 1990 base year. In these runs, we observed an anomalously large growth in energy costs ( $4-5 \%$ annually) during the initial decade - and therefore a reduction in the rate of GDP growth. For several of the demand categories, there were exceptionally large increases in the marginal costs of energy supply. As a result, the useful energy demands and total primary energy consumption decreased between 1990 and 2000 . The high growth rates for marginal and total energy costs were not the results of an increase in fuel prices or any other real change in the energy system environment. Instcad, these growth rates were spurious effects caused by the representation of base year investments in the MARKAL database.

To understand these results, one must examine the stand-alone version of MARKAL. It is a tool for strategic investment analysis. It focuses on the possible decisions that are open to the decision maker. The energy flows during the base year are introduced as a reference point, but there are no investment decisions to be made in this year. All investments are treated as "sunk costs", and all existing capacity is represented as residual capacity that requires no investment. The total energy costs for the base year will contain virtually no capital charges. There will therefore be demand categories where the shadow prices do not reflect the long-term marginal costs (including capital charges).

This treatment of residual capacity in MARKAL is efficient and well suited for the original model design. However, MARKAL-MACRO is calibrated by using base year data. If we exclude most investment costs during the base year, the calibration will be distorted. By understating energy costs, there will also be an understatement, of demand growth during the initial decade.

For demonstration purposes, we have adopted a simple procedure to make the base year data consistent with the need for linking both the primal and dual demand variables in MARKAL-MACRO. 
For each technology, we assumed that the base year investment is equal to the base year residual capacity divided by the lifetime of the technology. (This would be consistent with a steady state economy. If there is straight-line depreciation, the historically given capacities are retired at a constant rate.) The procedure works well for the demonstration case, and it leads to fairly consistent shadow prices. For future work, it would be desirable to refine this procedure, and to cross-check it against the investment statistics available for the energy sector.

\subsubsection{Endogenous and exogenous demands}

The MARKAL demand forecasts contain implicit assumptions on saturation effects, l.e., decoupling of GDP and dernand growth. MARKAL-MACRO considers this as an instance of autonomous conservation, and it describes saturation effects through the Autonomous Energy Efficiency Increase (AEEI) parameter. This is an explicit and easily documented input assumption for any scenario.

For the demonstration case, we have assumed that the $\mathrm{AEEI}=0.5 \%$ for all demai $d$ categories and time periods. In its present form, the model is designed so that the user is free to define scenarios where there is a different AEEI for each demand category. With a modest amount of additional GAMS programming, it would also be possible to allow for the AEEI to vary from one time period to the next.

Figure 4-3A shows the useful energy demands calculated by MARKAL-MACRO, and Figure 43B provides a comparison with the exogenous demands that drive the MARKAL stand-alone model. These exogenous demands were derived by assuming a $2 \%$ yearly increase in GDP, i.e., the same as the potential GDP growth assumed for MARKAL-MACRO.

There are differences between the two models that can be traced to price-induced conservation. However, there are four demand categories where MARKAL-MACRO consistently generates larger demand growth than is assumed for stand-alone MARKAL: ID: "Industrial process heat", R1: "Residential space heat", R6: "Commercial space heat and hot water", and T4: "Automobile transport". In these demand categories, we would have to assume AEEI rates of $1.4 \%-2.5 \%$ in order to have MARKAL-MACRO reproduce the demand assumptions used in MARKAL.

The MARKAL demand forecasts are usually based on bottom-up engineering calculations. For example, projections of the demand for space heat are usually based on models that involve assumptions on future building codes, climatic properties of building shells, rates of construction of new buildings and refurbishing or destruction of old buildings. They are also affected by socioeconomic 


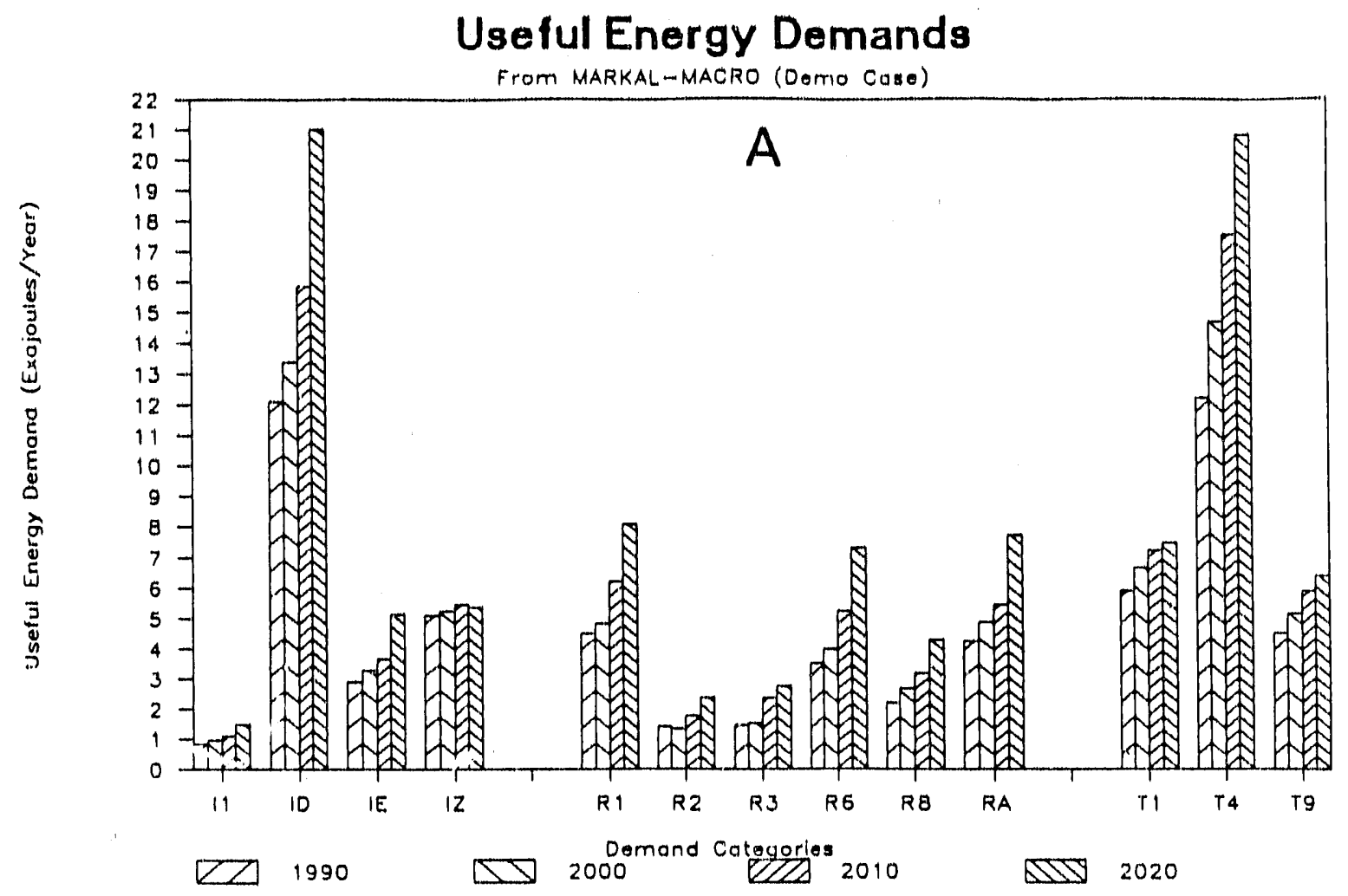

Difference in Useful Energy Demands

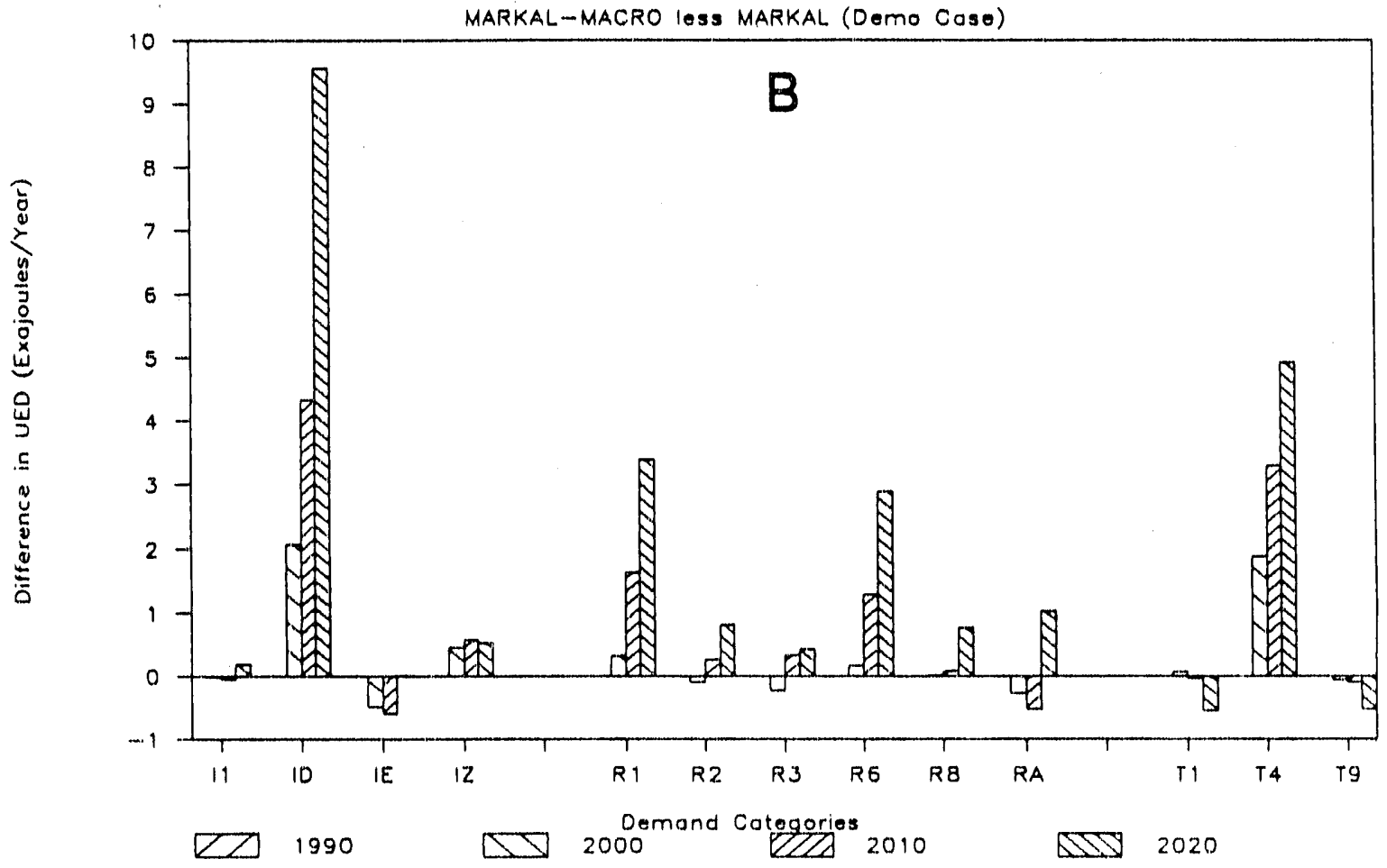

Figure 4-3A,B. Useful Energy Demands - MARKAL-MACRO va. MARKAL

The top figure shows the reaulta for 1990-2020 from MARKAL-MACRO. The bottom figure shows the differences between the MARKAL-MACRO UBeful Energy Demands and the Useful Energy Demands used as inputs to the MARKAL atand alone model. For an explanation of the demand categories, see caption to figure 4-4. 
parameters such as the size of the future family and the demand for second homes. The AEEI factor is not intended to replicate the detalls of these bottom-up approaches. Moreover, it can be difficult to distinguish between price-induced and autonomous conservation. The AEEI is a supplernent to the more sophisticated models. It provides a simple method for generating and documenting alternative scenarios, cross-checking the alternative bottom-up models, investigating the consequences of different assumptions on demand saturation and conservation, and providing a global allowance for new sources of demand.

\subsubsection{Prices}

For 12 out of 13 categorles, Figure 4-3A indicates that dernands grow more or less smoothly over time. For the remaining one ( $1 \mathrm{Z}$, "Hydrocarbons for non-energy use"), the demand remains nearly constant between 1990 and 2020.

Figure $4-4$ explains several of these results. The marginal costs for $\mathrm{IZ}$ increase by $35-50 \%$ over each decade, and this in turn reflects a specific view on the international outlook for crude oil prices. According to Figures 4-2A,B,C, these increases are so steep that one would expect transport demands to remain constant. But despite the rising price of crude oil, the marginal cost for end-use item T4 ("Automobile transport") remains constant. It turns out that this can in turn be traced to the MARKAL database in which it is supposed that the market will adopt increasingly more efficient auto transport technologies, and that these will neutralize the increase in oil prices. This leads us to infer that useful energy demand growth for $T 4$ should be close to the production growth factor $A_{i}(t)$. Figure 4-3A confirms this conjecture.

For several demand categories, there is a decline in marginal costs after the year 2000. This is attributable to the emergence of improved or new technologies, e.g. those for space heat and air conditioning.

\subsection{Demand technologiea and the representation of conservation}

The MARKAL model can choose from a menu of demand technologies to supply useful energy demands. For illustrative purposes, Figure 4-5 shows the choices made to satisfy the demand for residential space heat. Both MARKAL-MACRO and the stand-alone MARKAL solutions show that gas will continue to dominate this market. After the turn of the century, there is an improvement in the efficiency of gas heat pumps for space heat and air conditioning. This provides an additional 
SHADOW-PRICES FOR DEMANDS

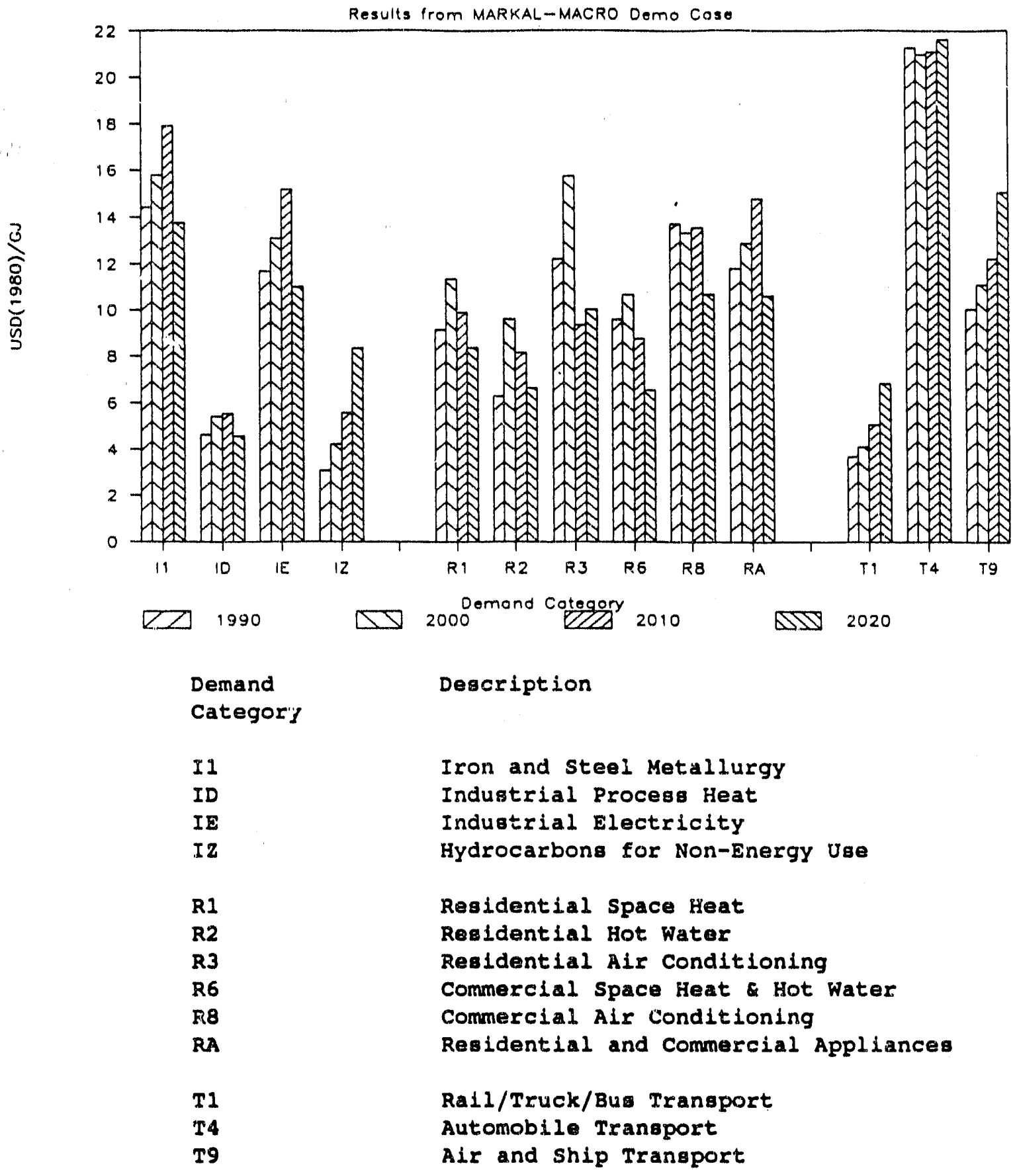

Figure 4-4. Shadow prices (marginal costs) 1990-2020 for the 13 demand categories. 
Space Heat: MARKAL-MACRO

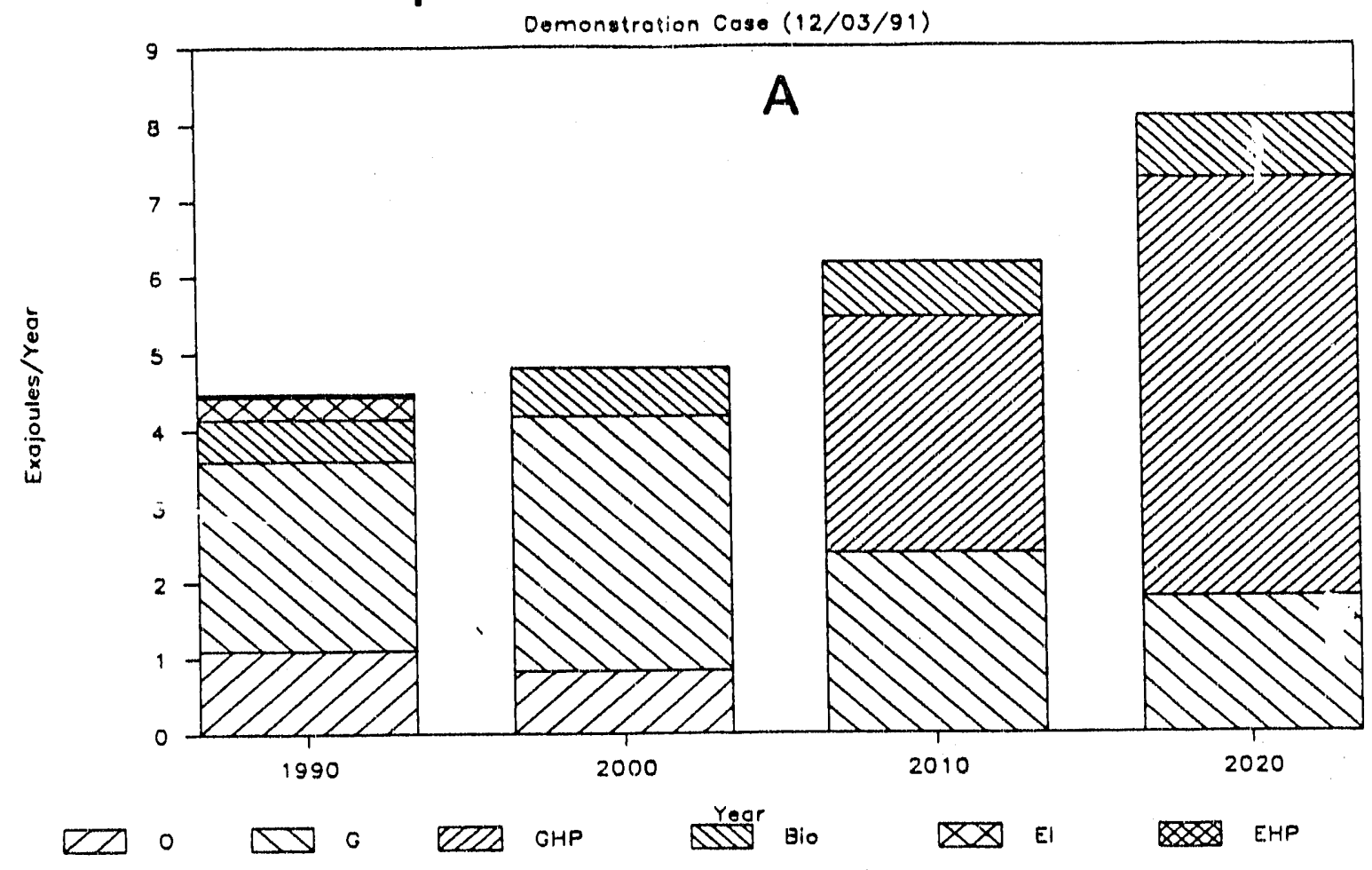

Space Heat: MARKAL (stand alone)

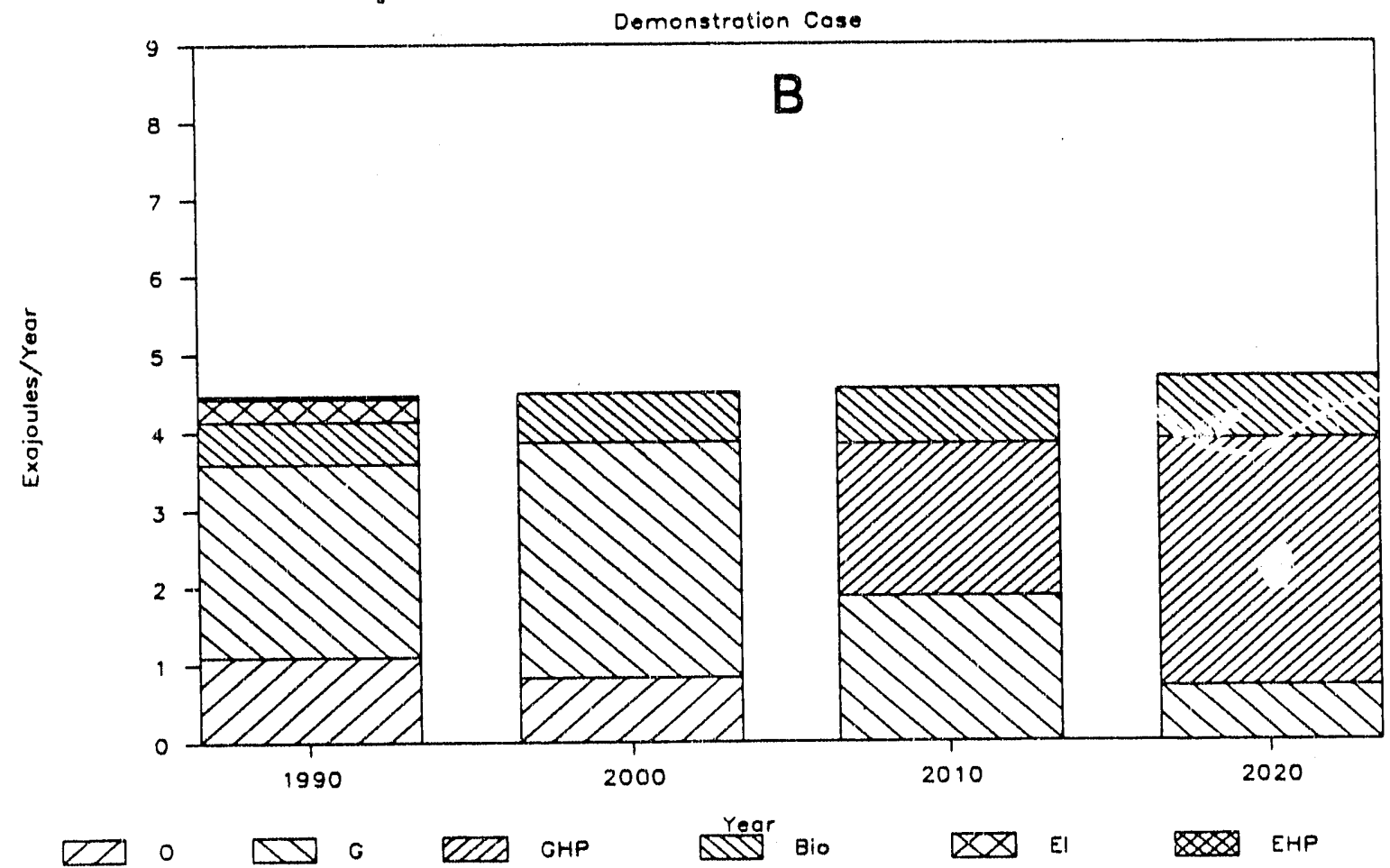

Figuxe 4-5A,B. Fuels and technologies - residential space heat. "O": oil burnar, "G": gas burner, "GHP": dual purpose gas heat pump space heat and air conditioning, "Bio": biomass burner, "El": electric resistance heating, "EHP": dual purpose electric heat pump - space heat and air conditioning. 
incentive for the use of gas in the residential market. Oil and electricity are phased out. Biomass is used in rural sieas. Most of the differences between the two solutions can be explain ad by different demand growth rates. The MARKAL demands for residential space heat can be reproduced in MARKAL-MACRO by assuming an $\mathrm{AEEI}=2.3 \%$. This leads to a large amount of autonomous conservation.

Before proceeding further, it is necessary to specify what is meant by the word "conservation". We propose to restrict this term to denote only those measures that actually reduce the total amount of final energy used to satisfy a given type of demand. The introduction of a renewable technology should not be counted as energy conservation, but rather as the replacement of a fossil or nuclear energy carrier. A heat pump is not a conservation but a substitution technology. It replaces either electricity or fossil fuels by solar energy. There are two reasons for adopting this terminology. First, MARKAL works in an engineering environment where energy balances and the first law of thermodynamics are important concepts for understanding and describing the properties of different technologies. Second, the energy may be renewable but limited in its availability. There will be situations where the available flow of renewable energy is a binding constraint, e.g., in hydroelectric systems where there is a positive shadow price associated with the availability of water during a specific point in the annual cycle of operations.

If we follow these definitions, the MARKAL database has no technical options for priceinduced conservation in the demand category "residential space heat", but there are several options for interfuel substitution. These demands can be satisfied by oil, gas, biomass or electricity.

For several demand categories other than residential space heat, the present MARKAL database includes both autcnomous conservation and also techuical options for price-induced conservation. The following two examples will illustrate how this affects the representation of conservation when we link MARKAL to MACRO.

In MARKAL, conservation can be described as an independent or an associaced technology. An independent conservation technology is not tied to any specific form of energy supply. Two examples would be double-pane windows and better insulation. They perform their function independently of the supply technology used for space heating. By contrast, an associated conservation option is an integral part of a supply technology, e.g., more efficient oil burners or automobiles with better mileage.

Figures 4-6 and 4-7 show the technologies selected in MARKAL-MACRO to satisfy the useful energy demands in two categories: industrial electricity and automobile transportation. Independent 


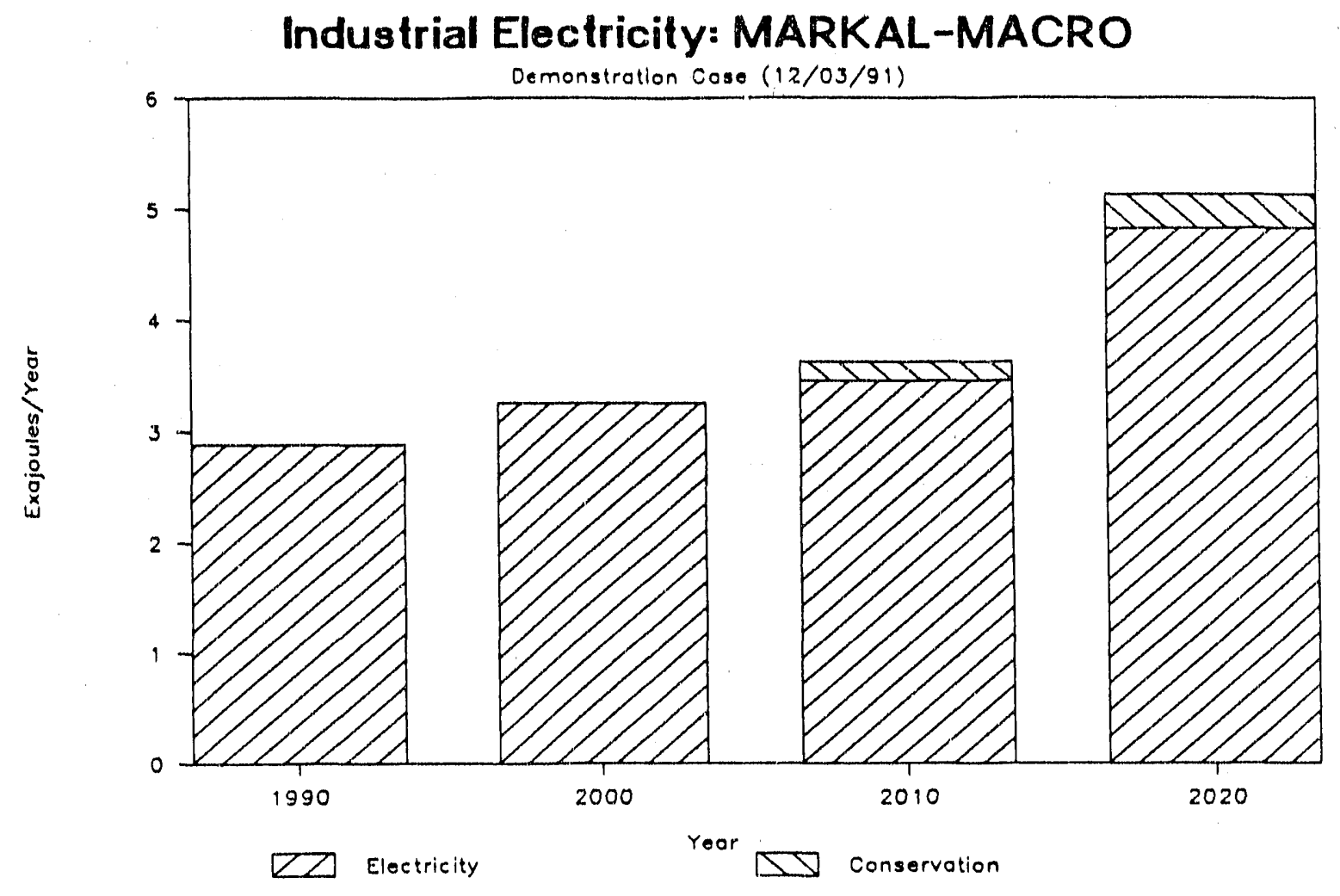

Figure 4-6. Industrial electricity

Aftex year 2000, conservation technologies are implemented to reduce the demand for electricity. 
Automobile: MARKAL-MACRO

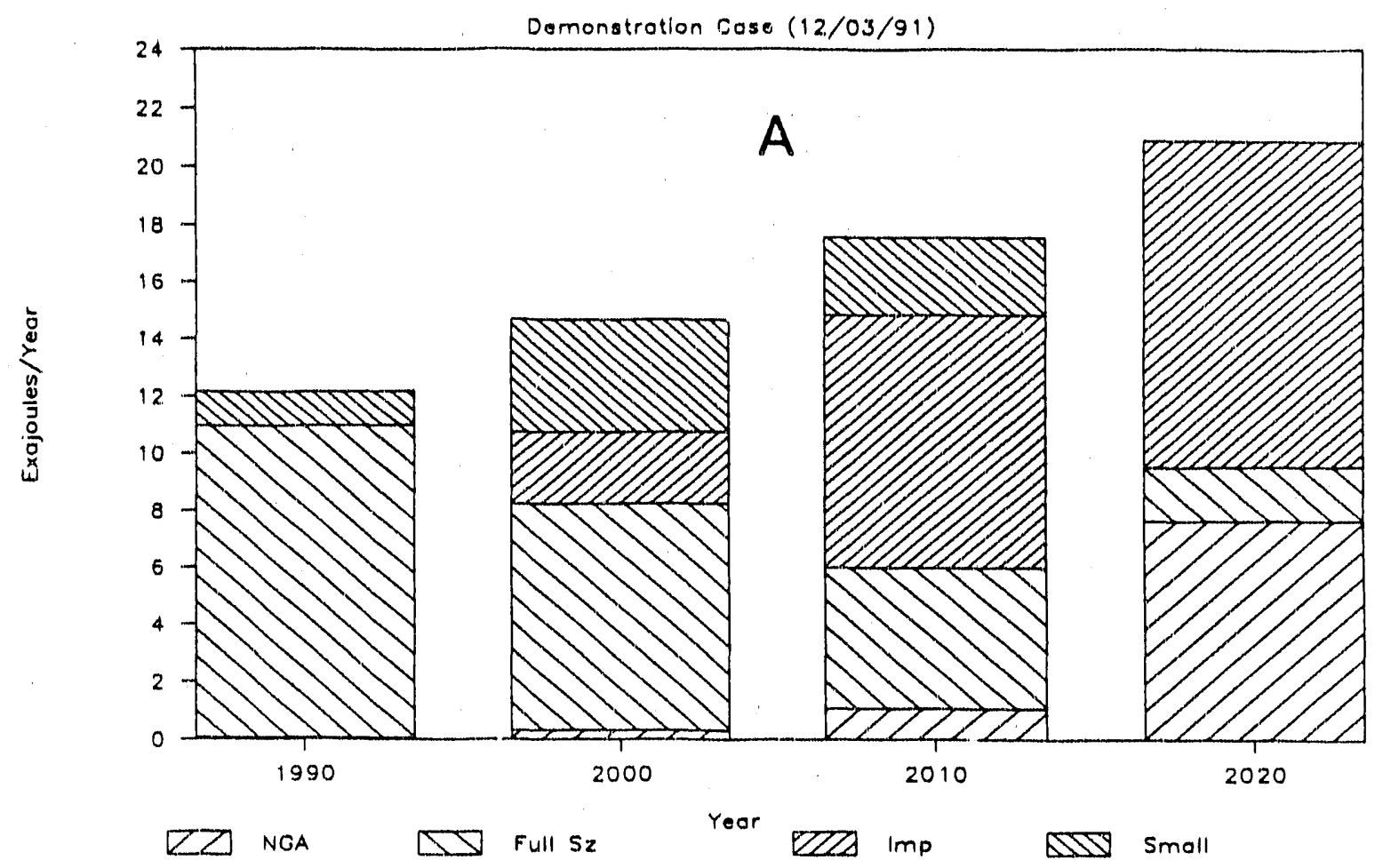

Automobile: MARKAL (stand alone)

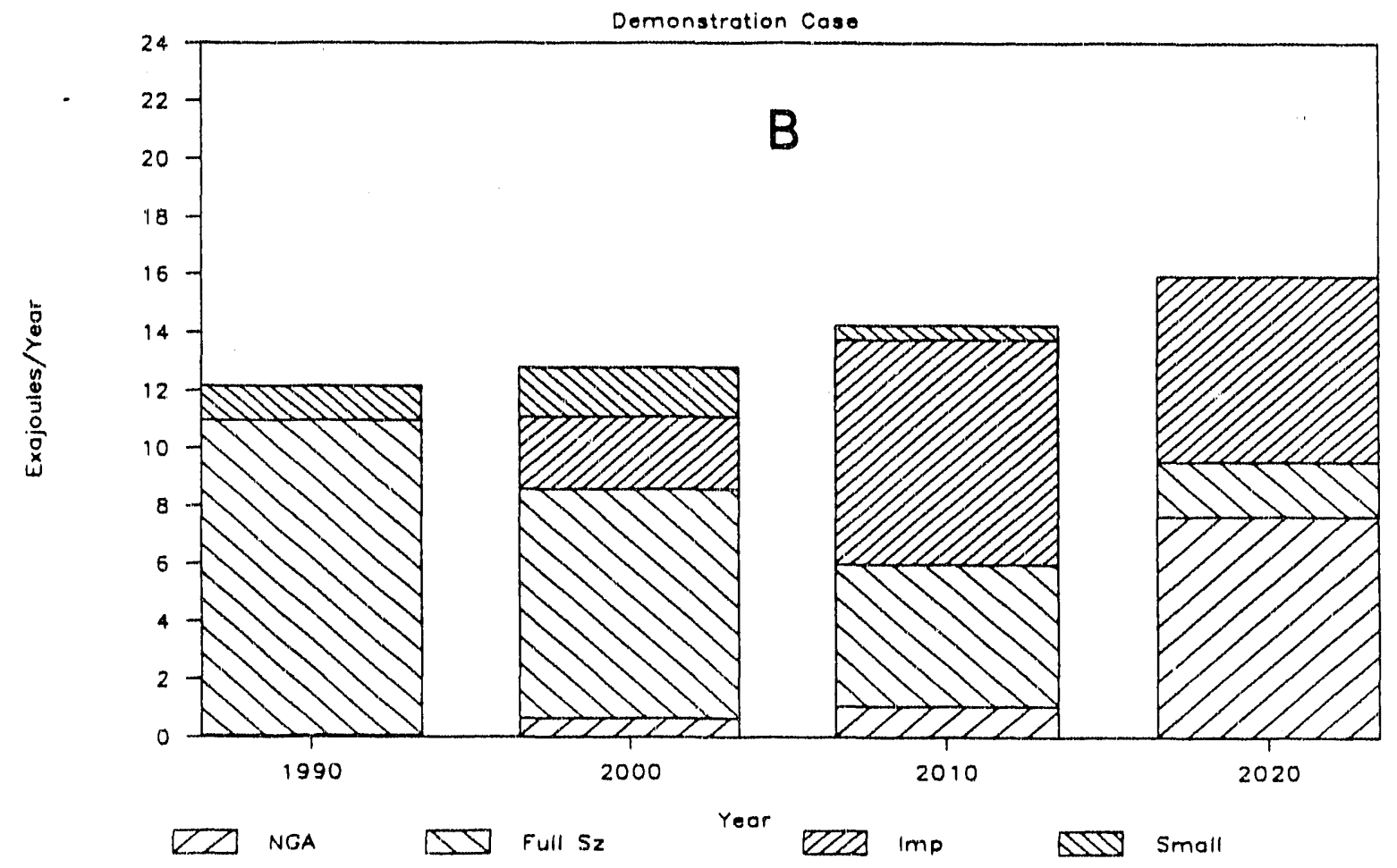

Figure 4-7A,B. Technologies - automobile transportation

"NGA": cars using natural gad, "Full Sz": full size cars using standard otto engines, "Imp": cars with improved otto engines - in 2020, about twice the milage of todays average fleet car, "Small": small cars with ot to engines. 
and associated conservation measures, respectively, are included in the optimal solutions for these two categories.

For industrial electricity, it is straightforward to show how the electricity conservation technology helps to reduce electricity demands. This is described as a separate technology in the database. It has its own distinct cost and technical attributes. Its effect upon the solution is clearly visible in Figure 4-6.

Automobile transportation is more complicated. By 2020, useful energy demands grow to 20.8 EJ, a $70 \%$ increase from the 1990 value of 12.2 EJ. This reflects the growth in services measured in terms of automobile-miles. However, the use of automotive fuels is reduced from $12.2 \mathrm{EJ}$ in 1990 to $11.2 \mathrm{EJ}$ in 2020. Some of this is autonomous conservation associated with the "improved Ottoengine", and some is interfuel substitution associated with the "natural gas engine" technology. Some of these trends are autonomous, and others are price-induced. The information about conservation is availatile in the database, but is not apparent in Figure 4-7.

MACRO handles conservation from a bird's-eye perspective through the macroeconomic production function. This is a natural way to allow, for example, for the impact of higher gasoline prices upon the average number of miles traveled. All demand categories are treated in a similar way, but there is no technological detail. MARKAL does not treat conservation in this comprehensive way, but the database may be very detailed for specific demand categories. The problem is how to salvage the engineering information from MARKAL for the linked model. We do not want to overlook any option, and we do not want to introduce double-counting by having the same options used both in MARKAL and in MACRO. We intend to explain alternative approaches to this problem.

\subsection{Primary Energy}

Figures 4-8A and 4-8B compare the primary energy demands from MARKAL-MACRO with those for the comparable MARKAL runs. The composition of fuel use is similar in both cases. Most of the variations may be explained by differences in useful energy demands.

For 2020, MARKAL-MACRO indicates a total that is about $30 \%$ higher than MARKAL. In effect, a greater amount of autonomous conservation is built into MARKAL than into the linked model. At the same time, we will have to reconsider the empirical evidence relating to market saturation and other phenomena that affect the AEEI. If this factor were to be, say, tripled from its base value of $0.5 \%$ per year, the linked model would lead to results that resemble the stand-alone version of MARKAL. 
In the year 2000, 6 EJ more natural gas are used in MARKAL-MACRO than in MARKAL itself. A comparison shows that there is a different time profile for the value of natural gas in the two models. MARKAL-MACRO saves natural gas from low-cost sources for use in the last period. The most likely explanation is that this is a horizon effect. The low-cost sources have a cumulative constraint which limits the total amount of gas, but does not restrict the pattern of extraction from one period to the next. The most likely remedy would be to combine the cumulative constraint with MARKAL's interperiod growth constraint for natural gas.

MARKAL invests in new nuclear capacity in 2010, but MARKAL-MACRO waits until the last period. We speculate that this may be due to a horizon effect in the MARKAL stand-alone model. MARKAL includes a salvage credit for long-lived investments such as nuclear reactors, and this may provide an artificial stimulus for early introduction.

Renewable energy provides a significant fraction of the increase in energy consumption, but the total quantity of its use is much the same in the two models. According to the database, these are low-cost technologies, and they tend to be pushed toward their upper bounds. The only exception is solar energy. Photovaltaics do not enter into any of the solutions. This means that solar energy is used exclusively for heating purposes, mainly heat pumps for space heating. The increased used of solar energy in the MARKAL-MACRO solution reflects the increased useful energy demand for space beating.

Carbon dioxide emissions are compared in Figure 4-9. The differences reflect the different use of fossil fuels in the two solutions, and ultimately the differences in useful energy demands. In MARKAL-MACRO, emissions increase slowly from their 1990 value. By contrast, the stand-alone MARKAL shows a monotonic decline of emissions. According to both models, there is a considerable amount of low-cost autonomous conservation available in the automobile sector, and this is the single largest consumer of fossil fuels. 


\section{Primary energy: MARKAL-MACRO}

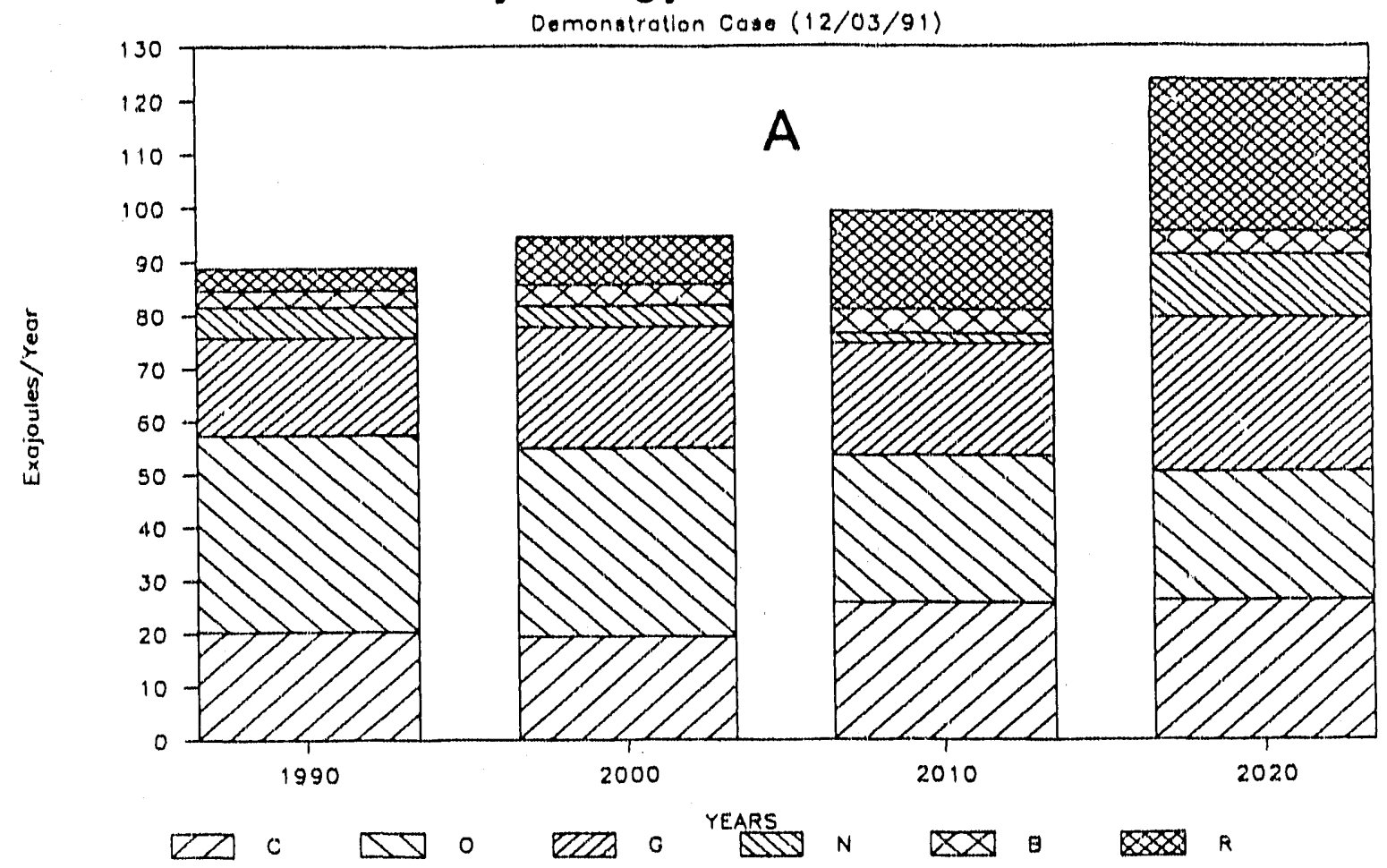

Primary energy: MARKAL (stand-alone)

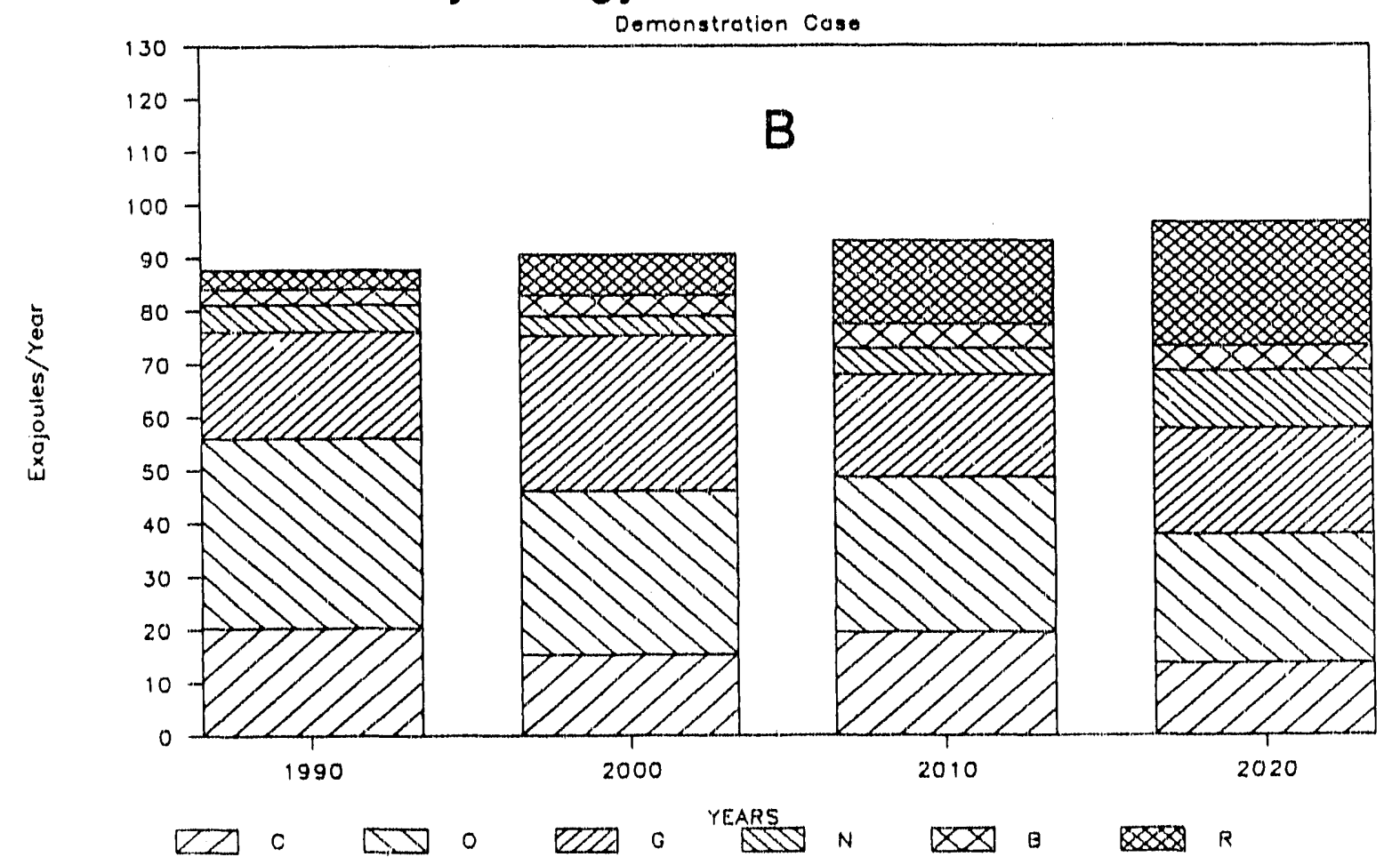

Figure 4-8A, B. Total primary energy demand.

"C": coal, "O": oil, "G": natural gas, "N": nuclear (fosail. equivalent), "B": blomaes, "R": other renewables - hydropower, geothermal power, wind power and solar heat (contributiona from renewable electric technologies are given in fogeil equivalent unitg). 


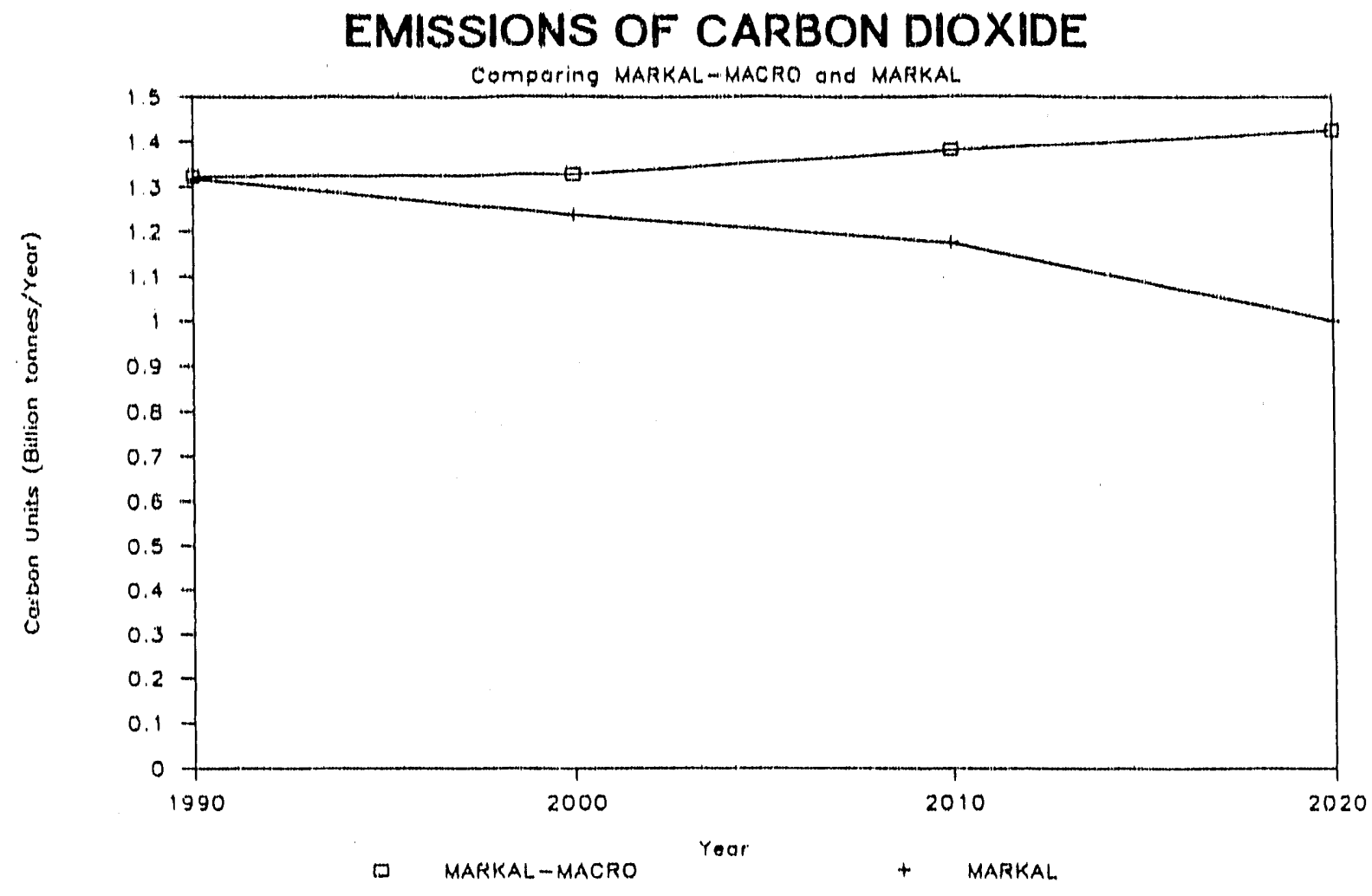

Figure 4-9. Carbon dioxide emisolons - comparing MARKAL-MACRO with atand-alone MARKAL. 


\section{Summary and conclusions}

This paper has demonstrated the feasibility of a formal hardlink between MARKAL (a systems engineering model) and MACRO (a longuterm macroeconomic growth model). The merger combines MACRO's aggregate vlew together with MARKAL's detalled arlalyslo of technlcal options for the energy system.

The differences between the engineer's and the economlst's perspectives are highllghted by the current discussion on corservation optione and their role In controlling CO2 emissions. The experience from this demonstration is limited, but It indicates that MARKAL-MACRO provides a tool to facllitate dialogue between the engineer and the economlst, and will also facilitate dialogue with pollcy makers.

Formal linkage ensures conslstency between energy supplies, demands and prices, and it Imposes a strong discipline upon the model user. We have seen that current MARKAL base year data management practices are incompatible with the benchmarking conditions for prices, quantities and interindustry payments for energy costs. MARKAL-MACRO includes a well-defined relation between demand growih and price changes. This is a prerequisite if we are to distinguish between price-Induced and non-price conservation.

In representing conservation within any model, there are two important guiding principles. The description should be inclusive but avold double counting. Further, the representation should be transparent. It should be easy to communicate whatever assumptions are made about saturation effects or specific conservation technologies. MACRO has a built-in mechanism that ensures transparency. Most MARKAL data bases contain considerable engineering information about conservation, but the information is usually not inclusive. Moreover, because of the richness of technological representations, it may be difficult to convey the meaning of model results to decision makers. In the future, it will be importiant to develop model procedures that rotain the conservation Information contained within MARKAL, but avoid double counting when this data base is linked to MACRO.

In addition to revising the treatment of conservation, we have found it necessary to modify the estimate of capacities that remain in place as a result of investment, decisions made during and pricr to the base year. These estimates of residual capacities will have to be coordinated with an update and with statistical quality control procedures for the data base itself. 
Some further developments are necessary to make the model routinely avallable as a tool for analyzing the U.S. energy system. MARKAL.MACRO is billingual. The demonstration project has shown that it is possible to translate back ard forth between the two languages OMNI and GAMS. It is ensy to change specific parameters, but cumbersome to change the model's structure, e.g. to shift from ten-year to flve-year sime periods. This would involve a falr amount of editing and managing of computer flles, and is Impractical for widespread use of the llnked model. Computer procedures should be developed for converting MARKAL-MACRO into a user-friendly format, These procedures have already been implemented for the stand-alone version of MARKAL, and it should not be difflcult to extend them to facilitate the management of inputs and outputs for the linked model. 


\section{Appendix A: Model Formulation}

Note: MARKAL-MACRO makes use of many of the same ideas as ETA-MACRO. Accordingly, this appendix incorporates some material directly from Manne and Richels (1992).

\section{MACRO decigion variables and notational conventions}

Among the decision variables, the maximand UTILITY is a scalar. All other MACRO variables are time-indexed, and refer to the projection periods $t=1(2000), 2(2010), 3(2020)$. Base year values are denoted by $t=0(1990)$. For simplicity, the time index $t$ is omitted from the MACRO variables listed below:

\section{UTILITY Sum of discounted logarithms of aggregate consumption}

Units of measurement for the following variables are \$ trilllons per year (measured in dollars of constant 1980 purchasing power):

$\begin{array}{ll}\text { C } & \text { Consumption } \\ \text { IV } & \text { Investment } \\ \text { EC } & \text { Energy costs } \\ Y & \text { Production, excluding energy sectors }\end{array}$

Units of measurement for the following variables are \$ trillions:

K Capital stuck

Units of measurement for the following variables are exajoules ( $10^{18}$ joules) per year:

$D_{\mathrm{dm}} \quad$ Demand for useful energy type $d m$ - before adjustment for autonomous energy efficiency improvements

Lower bounds are imposed upon almost all of the variables. Some of the lower bounds are zero. Others are positive. These help to reduce the solution time and/or to prevent program calls for undefined numbers, e.g. for the logarithm of zero. The latter class of lower bounds are essential during intermediate iterations, but are intended to be non-binding constraints at an optimal solution.

It may happen that the units of measurement are chosen so that the logarithm of consumption is negative. To allow for this unusual possibility, no lower bound is assigned to the UTILITY variable. It is allowed to take on negative as well as nonnegative values. 
All declsion varlables and sets are indicated by upper case letters; all parameters and running Indices by lower case letters. The parameters are specifled either directly or indirectly through a serles of data entrles which the user is free to modify. For example, the MACRO.INC file contalns the values for $g d p_{0}$ (the inltial GDP), kgdp (the intitial capltal-GDP ratio), kpus (capital's value share), depr (the annual depreciation rate for the aggregate capital stock) and the potential GDP growth rate (grow).

\section{MARKAL decision variables and constraints}

A special-purpose MPS to GAMS conversion program has been written so that all MARKAL variables retain their individual narnes (as well as their coefficients and bounds) generated by the OMNI-MUSS model generating system. For example, the first column in the MARKAL Iinear programming matrix is 1 EXPCOAC (coal exports during the base year). Within GAMS, this decision varlable is identified as $\mathrm{X}_{1 \mathrm{EXPCOAC}}$. That is, the symbol 1EXPCOAC is the first element in the GAMS set J. The generic decision variable is $X_{j}$. Similarly, the MARKAL row names are taken over as the elements in the GAMS set $I$. The input-output coufficient in row $i$, column $J$ is described as the parameter $a_{1 j}$. The right-hand side constant in row $i$ is rhs $s_{j}$ and the slack variable in this row is SLACK

MARKAL's cost and useful energy demand rows are connected to the MACRO submodel through special-purpose linkage equations. Along with the objective function and the accounting equations of MARKAL, these are described as non-binding rows (the GAMS set NBROWS). The other MARKAL equations are binding rows (the GAMS set BROWS). All of these binding rows are then incorporated through a single GAMS statement:

$$
\sum_{j \in J} a_{i j} x_{j}+\operatorname{SLACK}_{i}=\text { rhs }_{\mathrm{i}} . \quad(i \in \text { BROWS })
$$

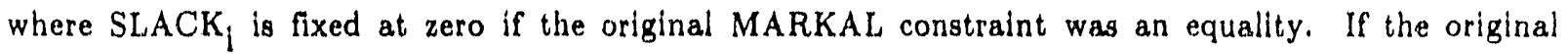
MARKAL constraint was a weak inequality, $\mathrm{SLACK}_{1}$ is either nonpositive or nonnegative depending on the direction of that inequality.

For each variable $X_{j}$, the GAMS program calculates a coefficient that describes its impact on the economy-wide energy costs in period $t$. This parameter is known as cost $\mathrm{jt}_{\mathrm{t}}$. It includes the annually recurring costs that appear in the original MARKAL model. It also includes the annual equivalent amortization payment commitments associated with the investment variables. This is a minor change, but seems necessary if we are to avoid "horizon effects" when we link the two models. MARKAL employs "salvage" coefficients to evaluate the worth of terminal capital stocks. In effect, this is a dual termination condition. By contrast, MACRO employs a primal termination condition. 
Following the horizon date, it is supposed that all the MACRO variables will grow at a constant geometric rate.

With these definitions, the following linkage equations determine the Impact of the MARKAL variables upon $\mathrm{EC}_{t}$, the total energy costs In period $t$ :

$$
\sum_{j \in J} \operatorname{cost}_{j t} X_{j}=E_{t} \quad(t=1990, \ldots, 2020)
$$

In MARKAI $I_{1}$ there is a fixed demand associated with each form of useful energy during each time period. In the linked model, we treat these demands as decision variables. There is one for each demand type during each time period. Accordingly, these decision variables are known as $D_{d m, t}$ To connect them with the MARKAL supply producing activities, we define the demand correspondence coefficients dmcor $\mathrm{dm}, \mathrm{t}, i$. These coefficients are unity if MARKAL row $i$ is assoclated with supplying the useful demand category $d m$ during time period $t$, and are zero otherwise. We may then link the MARKAL supply activities to the MACRO demand variables through the following equations:

$$
\sum_{i, j} d_{m \operatorname{cor}_{d m, t, 1}} a_{i j} x_{j}=\text { aeelfac }_{d m, t} D_{d m, t}
$$

where the coefficlents aeeifac $\mathrm{dm}, \mathrm{t}$ allow for any demand reductions associated with autonomous energy efficlency improvements.

To summarize: The binding rows are taken over directly from MARKAL. The cost coefficients are recalculated and linked to the macro energy cost variables. The energy supplies are related to the macro demand variables through a zero-one table of demand correspondence coefficients. For further details, see Appendix B. It includes excerpts from the following snecial-purpose "include"

\begin{tabular}{|c|c|}
\hline SETS.INC & column set I and row set $J$ (from OMNI-MUSS) \\
\hline NBROWS.INC & $\begin{array}{l}\text { non-binding rows (based on sets.inc) - the complement of the } \\
\text { BROWS set }\end{array}$ \\
\hline MAT.INC & matrix elements $a_{1 j}$, rhs $s_{i}$ and bounds (from OMNI-MUSS) \\
\hline COST.INC & $\begin{array}{l}\text { GAMS subroutine for calculating the } \text { cost }_{j t} \text { coefficients from } \\
\text { entries in the MAT.INC file }\end{array}$ \\
\hline DEMAND.INC & $\begin{array}{l}\text { demand correspondence coefficients, reference prices and } \\
\text { autonomous energy efficiency improvement rates }\end{array}$ \\
\hline MACRO.INC & macroeconomic coefficients \\
\hline
\end{tabular}
files: 


\section{MACRO constraints}

There is a single equation to define the maximand UTILITY, and there is a single constraint referring to the terminal period, TC. All other constraints are time-indexed. The MACRO constraints are as follows:

UTIL Discounted utility, sum over all projection periods

USE Uses of total output - allocated among expenditure categories

PRD Sources of total output - inputs to production

CAP Capital accumulation equation

TC Terminal condition on investment and capital stock

These constraints begin with the UTILITY maximand:

UtiL: $\quad$ UtiLiTY $=\sum_{t=1}^{\mathrm{T}-1}\left(u \mathrm{uf}_{\mathrm{t}}\right)\left(\log \mathrm{C}_{\mathrm{t}}\right)+\left(\mathrm{udf}_{\mathrm{T}}\right)\left(\log \mathrm{C}_{\mathrm{T}}\right) /\left[1-\left(1-\mathrm{udr}_{\mathrm{T}}\right)^{10}\right]$,

where the utility discount raie for period $t=u d r_{t}=(k p v s / k g d p)-\operatorname{depr}-g r o w_{t}$, and the utility discount factor for period $t=u d f_{t}=\prod_{\tau=0}^{t-1}\left(1-u d_{\tau}\right)^{10}$. The exponents of 10 allow for the fact that the first T-1 periods are each 10 years in length. The terminal period extends an infinite length of time after period $\mathrm{T}$. This is the reason for the divisor shown in square brackets.

A numerical example shows how the utility discount rate is determined if the following parameter values are adopted:

$$
\begin{aligned}
& \mathrm{kpvs}=\text { capital's value share } \quad=24 \% \\
& \mathrm{kgdp}=\text { initial capital-GDP ratio }=2.4 \text { years } \\
& \text { depr }=\text { depreciation rate } \quad=5 \% / \text { year } \\
& \text { net rate of return on capital } \quad=(24 \% / 2.4 \text { years })-5 \% / \text { year }=5 \% / \text { year } \\
& \text { grow }_{t}=\text { potential growth rate }=2 \% / \text { year } \\
& \therefore \quad \mathrm{udr}_{\mathrm{t}}=\text { utility discounc rate } \quad=3 \% / \text { year }
\end{aligned}
$$

The utility discount rate is chosen for descriptive rather than normative purposes. With the logarithmic single-period utility function, these values ensure that the optimal steady-state growth rate will coincide with that assumed for the potential GDP. Along an optimal path, the rate of decline in 
the present value of the marginal utility of consumption will equal the net marginal productivity of capital. (For a calculus-of-variations proof of this proposition, see Chakravarty (1969, p. 65).) Moreover, these discount rates mean that the economy-wide savings rate will adjust downward (upward) automatically if there is a drop (rise) in the potential GDP growth rate.

The USE equations specify that the gross value of production is to be used for current consumption, investment for building up the stock of capital, and interindustry payments for energy costs:

$\mathrm{USE}_{\mathrm{t}}$ :

$$
Y_{t}=C_{t}+I V_{t}+E C_{t}
$$$$
\mathrm{t}=0, \ldots, \mathrm{T}
$$

Since the variable $C_{t}$ enters only into the objective function and into equation $U_{S E}$, the dual variable for this constraint may be interpreted as the present value of the marginal utility of consumption during period t. First-order optimality conditions lead to the Ramsey rule for the optimal allocation over time between savings, investment and consumption. That is, the marginal productivity of capital determines the rate of decline of these dual variables from one period to the next. All other dual variables for period $t$ have a similar interpretation. They are present value prices. In order to convert them into future values, they must be divided by the dual variables for the USE $E_{t}$ constraints. According to the numerical example cited above, the net marginal productivity of capital is $5 \%$, and the dual variables for the USE $\mathrm{U}_{\mathrm{t}}$ constraints would decline by about $5 \%$ annually.

Aggregate output during period $t$ is determined by a nested CES (constant elasticity of substitution) production function. The first term indicates that capital and labor may be substituted directly for each other, e.g. through automation of labor-intensive tasks. The higher the wage rate, the more attractive it becomes to adopt automation. Similarly, the second term indicates that each of the end uses of energy may be substituted for the others. The higher the price of one of these forms, the more attractive it becomes to adopt another - or to engage in price-induced energy conservation through substituting more capital and labor per unit of output. The production function is of the following specific form:

$$
\begin{aligned}
\mathrm{PRD}_{\mathrm{t}}: \quad \mathrm{Y}_{\mathrm{t}}=\left[\operatorname{akl}\left(\mathrm{K}_{\mathrm{t}}\right)^{\rho \alpha}\left(\mathrm{L}_{\mathrm{t}}\right)^{\rho(1-\alpha)}+\sum_{\mathrm{dm}} b_{\mathrm{dm}}\left(\mathrm{D}_{\mathrm{dm}, \mathrm{t}}\right)^{\rho}\right]^{1 / \rho} & \\
& \mathrm{t}=1, \ldots, \mathrm{T}
\end{aligned}
$$

At its top level, this nested function has two terms. The first may be irterpreted as a value added aggregate of capital and labor based upon a unitary elasticity of substitution. The second is a 
separable energy aggregate. In effect, we are making the assumption of "want independence". See Frisch (1959).

The parameter $\alpha$ (also known as l.pvs) may be interpreted as the optimal value share of capital in the value added aggregate. The exponent $\rho$ is related to ESUB (the elasticity of substitution between the energy and the value added aggregates) through the following equation: $\rho=1-(1 /$ ESUB). For the concepts and terminology of macroeconomic production functions and neoclassical growth theory, see Allen (1968).

The labor force (measured in "efficiency units") is an exogenously specified index number, $\mathrm{L}_{t}$. Its values are: $\mathrm{L}_{0}=1$, and $\mathrm{L}_{\mathrm{t}+1}=(1+\text { grow })^{10} \mathrm{~L}_{\mathrm{t}}$.

Given the values for the two exponents $\alpha$ and $\rho$, a base year benchmarking procedure is employed to determine the coefficients $a k l$ and $b_{d m}$ in the production function. Let pref $d m$ denote the "reference" price of useful energy form $d m$ in the base year. Neglecting the time subscripts for this year, a first-order optimality condition implies that :

$$
\partial \mathrm{Y} / \partial \mathrm{D}_{\mathrm{dm}}=\left(\mathrm{Y} / \mathrm{D}_{\mathrm{dm}}\right)^{1-\rho} \mathrm{b}_{\mathrm{dm}}=\text { pref }_{\mathrm{dm}}
$$

Except for $b_{d m}$, each element in the preceding equation is known from the base year statistics or from other input parameters. After solving for $b_{d m}$, we employ the base year values directly within the production function. The base year labor force index is 1 . Since this nested CES production function is based upon constant returns to scale, we may rely upon exhaustion-of-product to solve the following equation directly for the parameter akl:

$$
\mathrm{Y}^{\rho} \quad=\operatorname{akl} \mathrm{K}^{\alpha \rho}+\sum_{\mathrm{dm}} \mathrm{b}_{\mathrm{dm}}\left(\mathrm{D}_{\mathrm{dm}, \mathrm{t}}\right)^{\rho}
$$

The CAP equations describe the dynamics of capital accumulation. Within each 10-year period, net new capital formation is determined by gross investment less depreciation. Let the annual depreciation rate be indicated by depr. Then the ten-year capital survival rate, tsrv $=(1-\operatorname{depr})^{10}$. Since investment is measured as an annual flow, an accumulation factor of 5 is applied to the beginning and ending rate of investment so as to determine net new capital formation during the decade as a whole:

$$
\begin{aligned}
& \operatorname{CAP}_{t+1}: \quad K_{t+1}=\operatorname{tsrv} K_{t}+5\left[\operatorname{tsrv} I_{t}+I_{t+1}\right] \quad t=0, \ldots, T-1, \\
& \text { where } \left.I_{0}=\text { (grow }+ \text { depr }\right) K_{0} .
\end{aligned}
$$


At the end of the planning horizon, a terminal constraint is applied to ensure that the rate of investment is adequate to provide for replacement and net growth of the capital stock during the subsequent periods.

TC:

$$
\mathrm{K}_{\mathrm{T}}(\text { grow }+ \text { depr }) \leq \mathrm{I}_{\mathrm{T}}
$$

In effect, it is assumed that the MACRO variables will grow at a constant geometric rate during the post-horizon period. This is a primal terminal condition. It reduces "horizon effects", but is not guaranteed to eliminate them entirely. For a more complete discussion of terminal conditions, see Svoronos (1985). 


\section{References}

R.G.D. Allen, 1968. Macroeconomic Theory. Macmillan, New York.

C. Berger, A. Haurie, G. Savard, R. Loulou, G. Lafrance and J.-P. Surprenant, 1987. "MEDEQ-MARKAL: Un Couplage Entre Deux Modeles Techno-economiques du Systeme Energetique du Quebec" R.A.I.R.O. Recherche Operationelle, Vol.21, No 1.

A. Brooke, D. Kendrick and A. Meeraus, 1988. GAMS: A User's Guide, Scientific Press, Redwood City, California.

S. Chakravarty, 1969. Capital and Development Planning, MIT Press, Cambridge.

R. Frisch, 1959. "A Complete Scheme for Computing All Direct and Cross Demand Elasticities in a Model with Many Sectors", Econometrica, 27.

L.G. Fishbone, G. Giesen, G. Goldstein, H.A. Hymmen, K.J. Stocks, H. Vos, D. Wilde, R. Zolcher, C. Balzer, and H. Abilock, 1983. "User's Guide for MARKAL (BNL/KFA Version 2.0)", BNL 51701, Brookhaven National Laboratory, Upton, N.Y.11973 and Forschungsanlage KFA-Julich, D-5170 Julich.

K.C. Hoffman and D.W. Jorgenson, 1977. "Economic and Technological Models for the Evaluation of Energy Policies", The Bell Journal of Economics, vol. 8, no. 12.

J. Johnsson, O. Bjorkquist, C.-O. Wene, 1992. "Integrated Energy-Emissions Control Planning in the Community of Uppsala", International Journal of Energy Research.

A.S. Manne and R.G. Richels, 1992. Buying Greenhouse Insurance: the Economic Costs of Carbon Dioxide Emission Limits, MIT Press, Cambridge.

W. Marcuse, L. Bodin, E. Cherniavsky, and Y. Sanborn, 1976. "Dynamic Time Dependent Model for the Analysis of Alternative Energy Policies" in: K.B. Haley (editor), Operational Research 75, North Holland, Amsterdam.

M.D. Rowe and D. Hill (eds), 1989. "Estimating National Costs of Controlling Emissions from the Energy System, A Report of the Energy Technology Systems Analysis Project, International Energy Agency", BNL 52253, Brookhaven National Laboratory, Upton, NY 11973.

A. Svoronos, 1985. Duality Theory and Finite Horizon Approximations for Discrete Time Infinite Horizon Convex Programs, Department of Operations Research, Stanford University, April.

G. Tosato, J. Brady, P. Essam, M. Finnis, G. Giesen, S. Rath-Nagel, H. Vos and D. Wilde, 1084. Energy After the Eighties, A Cooperative Study by the Countries of the IEA, Elsevier, Amsterdam.

C.-O. Wene, 1980. "The Optimum Mix of Conservation and Substitution: An example from Retrofitting Old Buildings", International Journal of Energy Research, Vol 4.

C.-O. Wene, 1989. "Using a Comprehensive Model for Community Energy Planning", in: L. Lundqvist, L.-G.Mattsson and E.A.Eriksson (eds.) Spatial Energy Analysis - Models for Strategic Decisions in an Urban and Regional Context, Avebury, Aldershot.

S. Yasukawa, O. Sato, Y. Tadokoro, T. Nagano, H. Shiraki, T. Kajiyama, Y. Nakano, and Y. Shimoyamada, 1989. "Emission Control Analysis Using the MARKAL Model of the National Energy System of Japan - Part II", in: M.D. Rowe and D. Hill (op. cit.). 
APPENDIX 8. Excerpts from MARKAL-HACRO input flles

SETS.INC FILE (from MPS to GAMS conversion program)

SET $\perp$ ।

PRICER

IANNCOST

3ANNCOST

SANNCOST

TANHCOST

IINVEST

3INVEST

SINVEST

7INVEST

1CPTE01

3CPTEOT

5CPTE01

7CPTEO9

SET J /

1EXPCOAC

3EXPCOAC

SEXPCOAC

TEXPCOAC

1EOTINV

3EOIINYS

SEOIINV

7EOIINV

-

1E01CAP

3EO1CAP

5E01CAP

7EO1CAP

-

NBROWS.INC FILE (edited from SETS.INC)

NBrous

Non-binding rows - to be eliminated from equality constraints

/PRICER

IANNCOST

3ANNCOST

5ANNCOST

TANNCOST

IINVEST

3INVEST

SINVEST

7IHVEST 


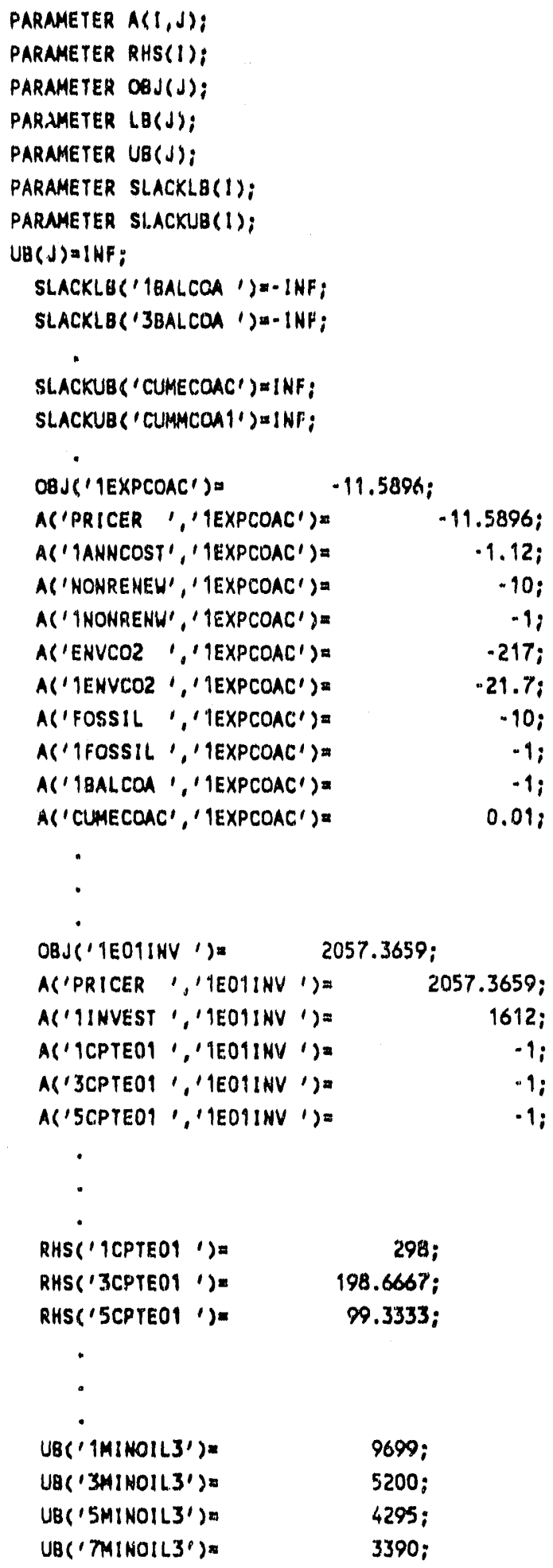


COST.INC FILE

SET

YR USEFUL LIFE - YEARS

I 10Y, 20Y, 30Y, BOY/

SCALAR ROR NET RATE OF RETURN PER YEAR - PERCENT 15,0/

TABLEE JL(J,") USEFUL LIVES AND YEAR-GY-yEAR ANNUITY PAYMENT COMHITMENTS

\begin{tabular}{|c|c|c|c|c|c|}
\hline & LIFE & 1990 & 2000 & 2010 & 2020 \\
\hline ITIOINV & 10 & 1 & & & \\
\hline 3TIaINV & 10 & & 1 & & \\
\hline STTOINV & 10 & & & 1 & \\
\hline MTOINV & 10 & & & & 1 \\
\hline \multicolumn{6}{|l|}{. } \\
\hline \multicolumn{6}{|l|}{ - } \\
\hline \multicolumn{6}{|l|}{. } \\
\hline IEOIINV & 30 & 1 & 1 & 1 & \\
\hline 3E01IHV & 30 & & 1 & 1 & $i$ \\
\hline SEOIIAV & 30 & & & 1 & 1 \\
\hline TEOIINV & 30 & & & & 1 \\
\hline
\end{tabular}

PARAMETERS

PV ONE-YEAR PRESENT VALUE FACYOR

CRF(d) CAPITAL RECOVERY FACTOR - INVESTMENT ACTIVITIES;

PV = 100/(100+ROR);

First payment is inade during the same year as capacity becomes avaliable. Spreadsheet calculation Indicates following results for $5 \%$ ROR.
LIFE CRF
10Y . 1233
$20 Y \quad .0764$
$30 Y .0620$
$80 Y .0486$ 


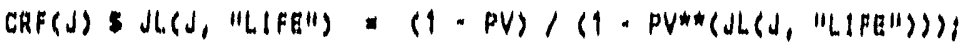

PARAMEYERS

ICOST(J) INITIAL INVESTHENT COSTS

$\operatorname{COST}(J, T P)$ ANNUAL EQUIVALENT COST COEPFICIENTS;

- Pirst we calculate the Initial investment costa.

$I \operatorname{cosT}(J)=A(" 1$ INVESTN, J) + A("IIINVEST", d)

$+A(" 5$ INVEST", ل) $+A($ "7INVESTH, $/)$;

- Then we caloulate their anmuallzed aquivalent.

$I \cos T(7)=I \operatorname{Cost}(4) * \operatorname{CRF}(7))$

- Now we calculate the year"by-year anmallzed Investment and operatine

- costs.

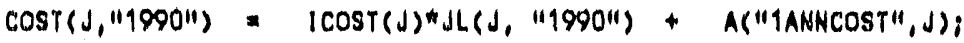

$\cos T(J, " 2000 ")=I \cos T(J) " J L(J, " 2000 ")+A(" 3 A N N \cos T ", J) ;$

$\operatorname{cosT}(J, " 2010 ")=I \operatorname{COST}(J) * J 1 .(J, " 2010 ")+A("$ SANACOST", J);

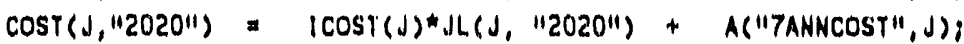

DISPI.AY COST; 
DEMAND.INC MILE

8ET

OR USEPUI. ENEROY DEMAND GATEOORIES - MACRO MOOHL

I 11, 10, IE, I2, R1, R2, R3, R6, R8, RA, T1, T4, T9/

"To avold reserved word "If", ohanged foedatocks ldentifler to "iz".

PABLL DOAT(DM,") DEMANO DATA

\begin{tabular}{|c|c|c|}
\hline \multirow{2}{*}{ • } & PREF & \multirow{2}{*}{$\begin{array}{l}\text { AEEI } \\
x \text { per your }\end{array}$} \\
\hline & - par us & \\
\hline 11 & 10.6 & .5 \\
\hline 10 & 3.0 & .5 \\
\hline IE & 10.6 & .5 \\
\hline 12 & 2.8 & .5 \\
\hline R1 & 8.5 & .5 \\
\hline R2 & 6.4 & .5 \\
\hline R3 & 7.4 & .5 \\
\hline R6 & 9.2 & .5 \\
\hline R8 & 7.4 & .5 \\
\hline$R A$ & 10.6 & .5 \\
\hline T9 & 3.4 & .5 \\
\hline$T 4$ & 21.0 & .5 \\
\hline TO & 2.5 & .5 \\
\hline
\end{tabular}

* PREF obtained from a prior maRKaL rin.

TABLE DMCOR(DM, TP, 1) - CCRRESPONDENCE BETWEEN MACRO AND MARKAL DEMAND NAMES

10EM!: 3OEMI1 SDEMII TDEMII

11.1990

19.2000

11.2010

1

11.2020

1

10.1990

10.2000

10.2010

10.2 .020

1

TOEMID 3OEMIO SOEMID TOEMIO

•

-

PARAMETERS DO(DM) Base year final demands - from MARKAL;

$D O(D M)=.001 * \operatorname{SUM}(1, \operatorname{RHS}(1) * D M C O R(D M, N 1990 ", 1))$

DISPLAY DO; 


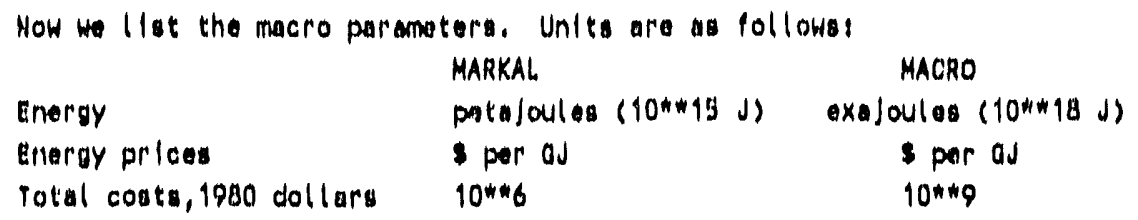



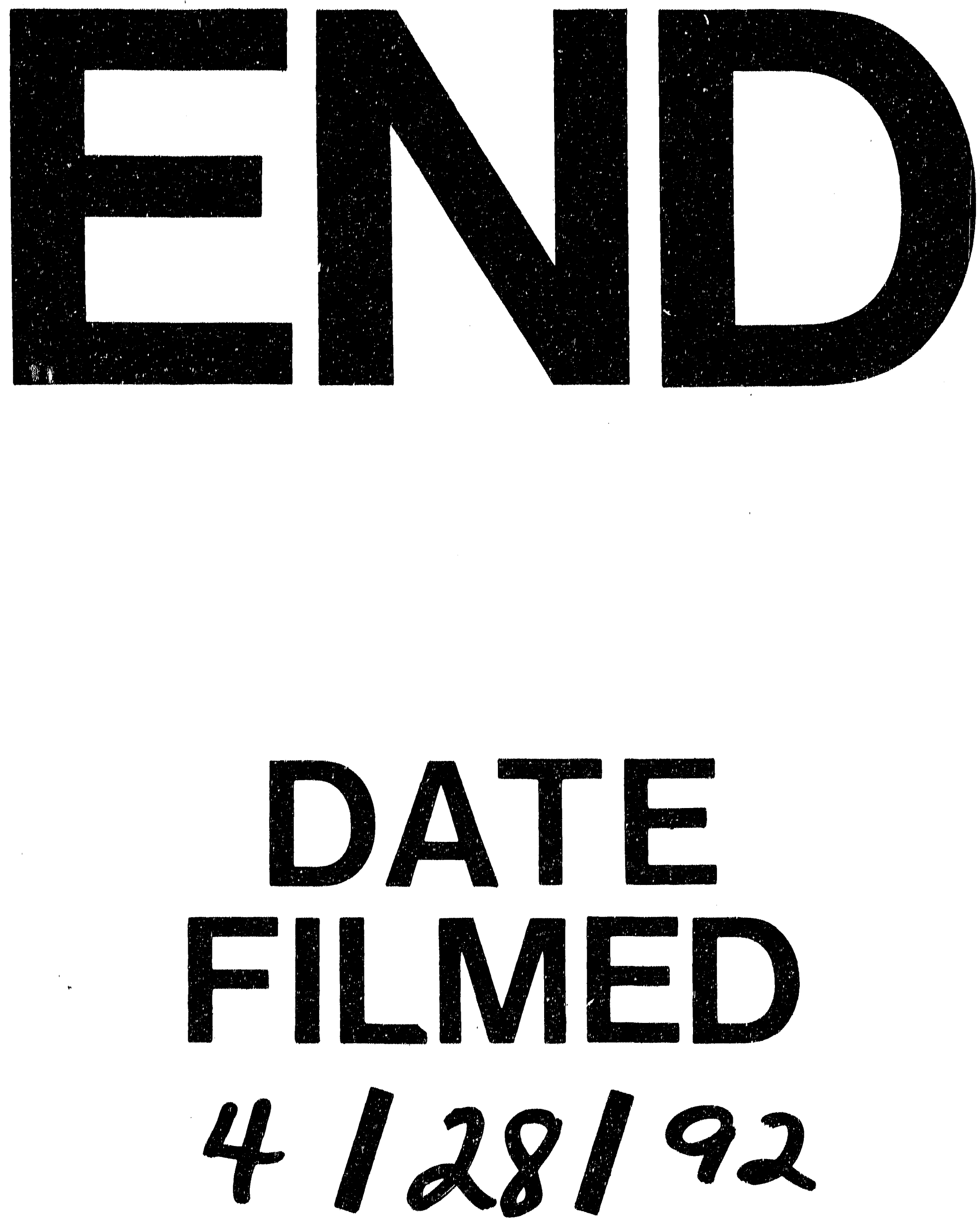
